\title{
A Literature Survey on Open Platform Communications (OPC) Applied to Advanced Industrial Environments
}

\author{
Isaías González $^{1, *(\mathbb{D})}$, Antonio José Calderón ${ }^{1}(\mathbb{D})$, João Figueiredo ${ }^{2,3}$ and João M. C. Sousa ${ }^{3}$ (D) \\ 1 Department of Electrical Engineering, Electronics and Automation, University of Extremadura, \\ Avenida de Elvas, s/n, 06006 Badajoz, Spain; ajcalde@unex.es \\ 2 Centre of Mechatronics Engineering-CEM, University of Évora, R. Romão Ramalho, 59, \\ 7000-671 Évora, Portugal; jfig@uevora.pt \\ 3 IDMEC, Instituto Superior Técnico, Universidade de Lisboa; 1049-001 Lisboa, Portugal; \\ jmsousa@tecnico.ulisboa.pt \\ * Correspondence: igonzp@unex.es; Tel.: +34-924-289-600
}

Received: 31 March 2019; Accepted: 4 May 2019; Published: 8 May 2019

\begin{abstract}
Extensive digitization and interconnection through networks have ushered in a number of new paradigms over the last years: Internet of Things, cyber-physical systems, Industry 4.0, etc. These challenging systems rely on an effective information communication between distributed components. Therefore, the heterogeneity of entities, both hardware and software, must be handled to achieve an operative interoperability and a proper behavior. However, there is also a heterogeneous availability of solutions; different technologies, protocols, and architectures aim to achieve a seamless interconnection. Henceforth, the standardization still requires great efforts from industrial and scientific environments. In this sense, the interface of the open platform communications (OPC) has supported connectivity for automation and supervision infrastructures for more than two decades. The OPC comprises the so-called classic OPC, the original protocol, as well as the last specification, unified architecture (UA). The widespread utilization of the classic OPC together with the powerful functionalities of OPC UA, make the latter one of the main candidates to lead the standardization and systems integration. This paper presents a survey of recent OPC-based systems reported in scientific literature for different domains as well as research projects. The goal of this paper is to provide a broad perspective about the OPC' applicability and capabilities in order to support the decision about communication interfaces. The results are analyzed and discussed putting special attention on the aforementioned new paradigms. Finally, the main conclusions and open research directions are highlighted.
\end{abstract}

Keywords: industrial communications; OPC UA; classic OPC; SCADA; interoperability; Internet-of-Things; Industry 4.0; automation

\section{Introduction}

Digitization and interconnection through networks are increasingly affecting industries. As the advances in information and communication technologies (ICTs) penetrate the whole chain of processes, the evolution towards new paradigms is unstoppable: Internet of Things (IoT), cyber-physical systems (CPS), Industry 4.0, big data, etc. Namely, CPS combine mechatronics and ICTs to control physical processes and systems, designed as a network of interacting software and hardware components, devices, and systems [1]. This approach applied to production systems is named cyber-physical production systems (CPPS) [2-4] or industrial CPS (ICPS) [5-8]. 
Even, the advent of the fourth industrial revolution is being performed by the penetration of information, communication, and control technologies (ICCT) into a networked industrial environment. This revolution is commonly referred to as Industry 4.0; however, such a term is a label similar to the German strategic program called Industrie 4.0 [9].

In addition, there are some initiatives around the world to develop the next-generation of industrial facilities: Nouvelle France Industrielle [10] in France, Connected Industry 4.0 [11] in Spain, China Manufacturing 2025 [12] in China, Smart Manufacturing Leadership Coalition [13] in the US, and the Japanese Robot Revolution Initiative [14] that has agreed to cooperate in the field of IoT/Industry 4.0 with the German initiative.

In this context, physical operative technology (OT) and cyber information technology (IT) are integrated in order to seamlessly collaborate. Operative technology is composed of shop floor devices like automation units, sensors and actuators, whereas software management systems like manufacturing execution systems (MES), enterprise resource planning (ERP), and supervisory control and data acquisition systems (SCADA) constitute the IT level. The OT/IT connectivity and interoperability are a challenging task for Industry 4.0 implementation that receives important research efforts [15].

Systems integration requires an enormous effort, especially for large-scale infrastructures. In general, these facilities are complex, vast networked systems that comprise a vast number of devices and applications with different communication protocols. Therefore, data acquisition, exchange, and processing are achieved in a distributed way between heterogeneous data sources and consumers. Cyber-physical systems and IoT are represented by platforms that are integrated through connectivity protocols that permit a wide sharing of information among different devices [16]. In fact, a big challenge in these innovative scenarios is related to the wide heterogeneity of devices, operating systems, platforms, and services [17]. Interoperability is one of the major advantages of Industry 4.0 [18], but proprietary approaches must be replaced by open and standardized communications solutions to make it a successful reality $[19,20]$. Consequently, standardization is essential for the real development and deployment of these systems. The lack of standards is actually considered a big issue, so research efforts must be performed in the direction of defining standard protocols, languages, and methodologies to enable the full potential of such concepts [17].

There is also heterogeneity referred to the availability of diverse communication protocols devoted to the shop floor like OPC, MTConnect, message queue telemetry transport (MQTT), distributed network protocol (DNP3), as well as modelling information languages, such as the common information model (CIM) or the unified modelling language (UML). Even, for these paradigms, there are numerous conceptual frameworks to perform their orchestration and deployment. For instance, the reference architectural model for Industry 4.0 (RAMI) [21], the industrial internet reference architecture (IIRA) of the industrial internet consortium [22], and many others [7,23-25] that are continuously enriching the possibilities of these approaches.

Despite the fact that each one of the available options has pros and cons, such heterogeneity constitutes a significant obstacle for a real standardization and seamless interconnection of the ecosystems. This difficulty must be overcome when facing the design and systems integration of infrastructures under these advanced approaches. The selection of the communication interface to achieve an effective interoperability and heterogeneity management is a transcendental decision that seriously affects aspects such as economic costs, maintainability, expandability, security, and resilience.

In this sense, open platform communications (OPC) has proven to be an effective communications middleware mainly in industrial applications. Due to its powerful functionalities, the last specification, called unified architecture (UA), is one of the main candidates to lead the standardization and systems integration for present and future frameworks.

Open platform communications is an industrial communication interface also known as open process control, or openness, productivity, collaboration. It has even been termed the network glue for control systems [26]. Open platform communications provides a technology to support interoperability and heterogeneity in control and automation applications, mainly devoted to industrial 
manufacturing. The so-called classic OPC was developed by an industrial automation industry task force in 1996 to provide a communication protocol for personal computer (PC)-based software applications and automation hardware. Currently, OPC comprises ten specifications that are established and managed by the OPC Foundation [27]: Data access (DA), historical data access (HDA), alarms and events (A\&E), XML-data access (XML-DA), data exchange (DX), complex data (CD), security, batch, express interface (Xi), and unified architecture (UA). The classic OPC includes the first eight specifications and the OPC DA is the most widely applied. In fact, initially the term OPC corresponded to object linking and embedding (OLE) for process control. It is primarily used to provide real-time access to process control and manufacturing data. One of the main reasons for the rapid diffusion of OPC classic specification was also the most criticized aspect: it was based on Microsoft's distributed component object model (DCOM), and thus, platform-dependent and not suitable for use in cross-domain scenarios and for the Internet [28]. Classic OPC is nowadays a legacy technology, and hence, is not further developed.

Far from being left behind, the last specification, OPC UA, is gaining ever-increasing attention. Developed as the successor to classic OPC, UA specification was released in 2006 and is an IEC international standard of the international electrotechnical commission (IEC), namely, IEC 62541. This new version is intended to provide greater interoperability, eliminating MS-Windows dependency; OPC UA is able to operate in different operative systems like UNIX-based ones. This specification is built around service-oriented architecture (SOA) and is based on web services, making easier the implementation of OPC connections over the Internet. As pointed out in Reference [29], classic OPC did not attract much interest in research communities but the availability of connection to the Internet made OPC interesting. In fact, since OPC UA was defined, it is receiving growing research efforts and is intended to replace classic OPC. The highly configurable address space is designed to allow for the creation of complex networks of data [4]. Moreover, OPC UA has improved features concerning security-like encryption, authentication, and audition [27].

It is worth emphasizing that within the present paper, OPC classic and OPC UA are grouped from the point of view of applications, not concerning their absolutely different conceptual design. In the same regard, it must be noted that the technical particulars of OPC specifications would be superfluous for the objectives of this paper, whereas detailed information can be found in reference [27].

The inclusion of this standard assures the scalability of the infrastructure and allows later expansions from diverse hardware/software products. Some of the main benefits of OPC utilization are: wide support from hardware and software manufacturers, open connectivity, generality, scalability, modularity, easy configuration, just to name a few. Refer to reference [24] for further details. Figure 1 depicts the general layout of communication using the classic OPC protocol. The hardware devices act as data sources and the software applications play the role of data consumers whereas the OPC interface acts as connectivity middleware, enabling the data flow. i.e., a data hub is materialized by OPC, around which devices and applications access through their OPC interfaces. Data consumers are commonly software applications that cover process monitoring and scheduling environments, i.e., SCADA systems, human-machine interfaces (HMIs), as well as ERP programs. Concerning OPC-enabled hardware (data sources) programmable logic controllers (PLCs) are the dominant type of automation physical devices thanks to their reliable and robust operation. Other field devices to be interfaced through OPC are data acquisition cards (DAQs), remote input/output units, robot controllers, intelligent electronic device (IED), radio frequency identification (RFID) readers, etc. Indeed, most of industrial equipment manufacturers provide OPC functionalities. By means of the OPC, the client applications access and manage the field information without need of knowledge about the physical nature of data sources [24].

Beyond the typical industrial application, the capabilities of OPC technology allow extending its application to other kinds of environments, such as energy automation, virtualized environments, educational systems, building automation, and many others. In fact, within the current vortex of technological evolution, OPC UA is targeted as a fundamental technology by many authors of the reviewed literature. 


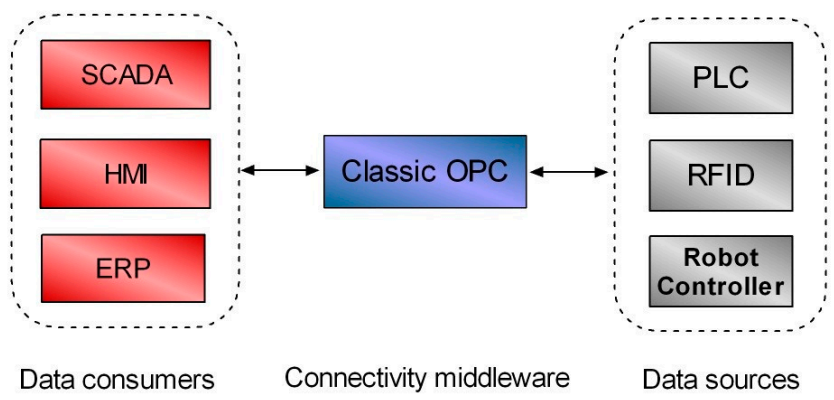

Figure 1. Classic open platform communications (OPC)-based communication scheme in automation system.

There is a large amount of journal and conference papers reporting OPC application cases; however, scarce reviews and surveys concerning strictly OPC features can be found in the literature. Each one of them focuses on specific features or domains, for instance, security [30], performance [28], or specific applications like maintenance [31]. An exception is the work of Schwarz and Börksök [29], a survey on OPC reporting details about the specifications and outlining research lines. Although it is a valuable paper, it is brief and a technical specifications-centered paper, so it does not cover the full scope of how OPC may be used.

From authors' viewpoint, given the widespread utilization of classic OPC and the powerful capabilities of OPC UA, these standards deserve a work focused on reviewing recent and relevant application examples regardless of the particular domain, and also the main open research trends. To the best of our knowledge, there is no existing work addressing this issue.

This paper presents a survey of the most meaningful research and development (R\&D) works covering all the widely diverse scopes where OPC has been recently applied. Furthermore, nowadays the role of OPC UA is receiving even higher relevance due to its interplay in the main challenges of the technological and scientific world, namely, IoT, CPS, Industry 4.0, etc. This issue is also discussed.

The main goal of this paper is to provide a broad perspective about OPC applicability and capabilities in order to support the decision about communication interfaces when designing advanced automation infrastructures. In a more detailed manner, this work provides the following contributions: (i) An analysis of scientific literature was carried out to highlight the importance of OPC; (ii) A categorization of the most significant papers was performed according to the application scope; (iii) A comprehensive background on recent OPC-based systems was afforded, useful for researchers, academics, and practitioners; (iv) A panoramic view on trends and open research issues of OPC UA is provided, mainly related with CPS, IoT, and Industry 4.0.

The remainder of the paper is organized as follows. The materials and method used for the survey of OPC applications reported in the scientific literature are expounded in Section 2. In Section 3, the achieved results are described, including recent OPC-related R\&D projects. Section 4 deals with the discussion of the reported results jointly with the trends and open research issues regarding OPC UA. Finally, the main conclusions are addressed.

\section{Materials and Methods}

Aiming to illustrate the presence of OPC technology in the scientific literature, an analysis of the available publications, mainly from journals and conferences, was carried out. This survey used different bibliographic databases, namely, Scopus, Web of Science, Google Scholar, Institute of Electrical and Electronics Engineers (IEEE) Xplore, and Science Direct. Among these data sources, Scopus indexes 70 million items from more than 5000 publishers and contains 1.4 billion cited references dating back to 1970 . So, for a clearer illustration of the conducted task, the statistics given hereafter have been built on the results provided by this database.

Due to the diverse ways of referring to OPC communication, the query in the fields of meta-data (Title, Abstract, and Keywords) included a number of variants of terms like "OPC interface", 
"OPC protocol", "OPC standard", “OPC communication", "OPC UA", etc. In addition, some excluding terms were used to avoid acronyms with different meanings. In order to illustrate the performed searching tasks, the exact query for Scopus is now given:

(TITLE-ABS-KEY ("OPC interface") OR TITLE-ABS-KEY ("OPC protocol") OR TITLE-ABS-KEY ("OPC standard") OR TITLE-ABS-KEY ("OPC UA") OR TITLE-ABS-KEY ("OPC server") OR TITLE-ABS-KEY ("OPC channel") OR TITLE-ABS-KEY ("OPC technology") OR TITLE-ABS-KEY ("OPC communication") OR TITLE-ABS-KEY ("OPC link") AND NOT TITLE-ABS-KEY (aerosol) AND NOT TITLE-ABS-KEY (purification) AND NOT TITLE-ABS-KEY ("optical proximity") AND NOT TITLE-ABS-KEY ("optical phase") AND NOT TITLE-ABS-KEY (photoconductor) AND NOT TITLE-ABS-KEY (lithography) AND NOT TITLE-ABS-KEY (oligodendrocyte) AND NOT TITLE-ABS-KEY (cancer) AND NOT TITLE-ABS-KEY (cement) AND NOT TITLE-ABS-KEY (concrete) AND NOT TITLE-ABS-KEY (oropharyngeal) AND NOT TITLE-ABS-KEY ("phase shift") AND NOT TITLE-ABS-KEY ("optical proximity correction") AND NOT TITLE-ABS-KEY ("optical plankton counter") AND NOT TITLE-ABS-KEY (photolithography)).

A total number of 866 publications were found in Scopus, distributed according to their type as depicted in Figure 2. The conference papers represented around $66.5 \%$ of published papers, whereas $32 \%$ corresponds to journal publications. The third group (others) contained books, technical notes, and other kinds of works. Relevant contributions published in conferences without public access may have been left unnoticed. It must be noted that we surveyed not only works related to OPC applications but also to potential usage of this interface within the innovative scenarios aforementioned. Moreover, some of the references correspond to web sites where open code for OPC UA implementations was available or to recent press releases related to OPC UA developments, but they were not included in these statistics.

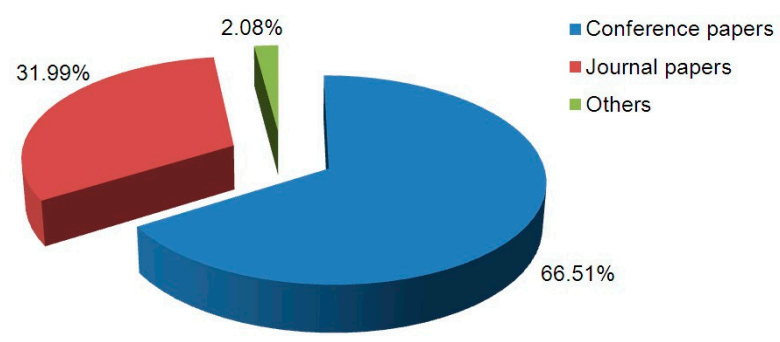

Figure 2. Distribution of publications according to their type.

Figure 3 shows the evolution of OPC-related papers since the creation of the classic OPC (1996) up to 2017. A rapid increase occurred in 2006, from 16 to 29 publications, which indicated that OPC attracted special attention from that year, starting a growing trend. In this way, the number of publications increased year by year up to 2013, with a peak of 89 . After that year, the amount of contributions fluctuated until reaching the maximum value in 2017, 91, as can be observed. It should be noted that during the last years, instead of reporting applications of classic OPC, many of the publications were devoted to developments of OPC UA related to integration with other standards and to emerging trends (IoT, CPS, etc.) as exposed in the next sections. In fact, the interplay of the UA specification with those innovative trends makes OPC UA-related papers a leading research area in the scientific literature. On the other hand, Figures 4 and 5 show the distribution of publications, expressed as percentages, between the top six subject areas and the top six countries, respectively. As it is well known, an article belongs to more than one area, so the final percentage is higher than $100 \%$. As it can be seen, Engineering is the area to which more papers are devoted (65.82\%), whereas China is the country where the largest percentage of publications is generated, $32 \%$. Computer Science and Germany are in the second position in the respective graph. 


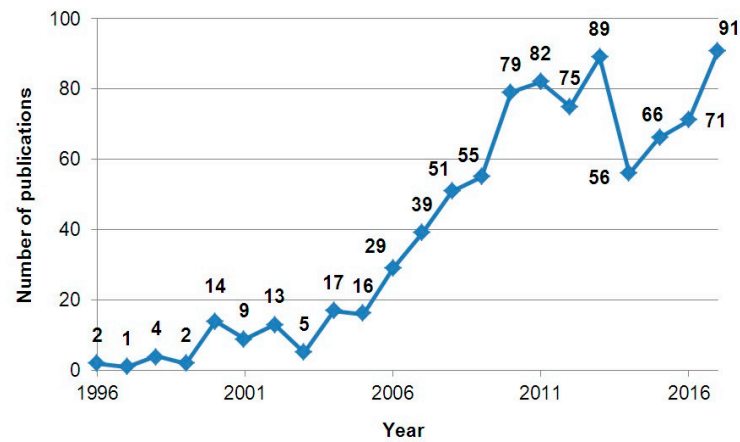

Figure 3. Number of publications per year from 1996 to 2017.

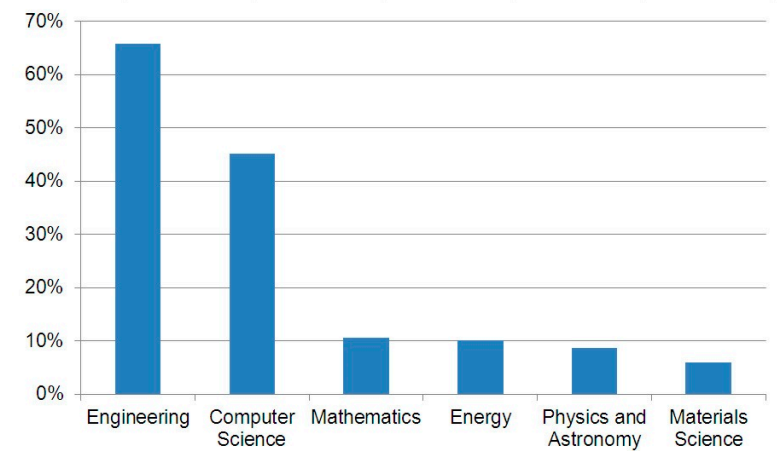

Figure 4. Distribution of publications between the top six subject areas.

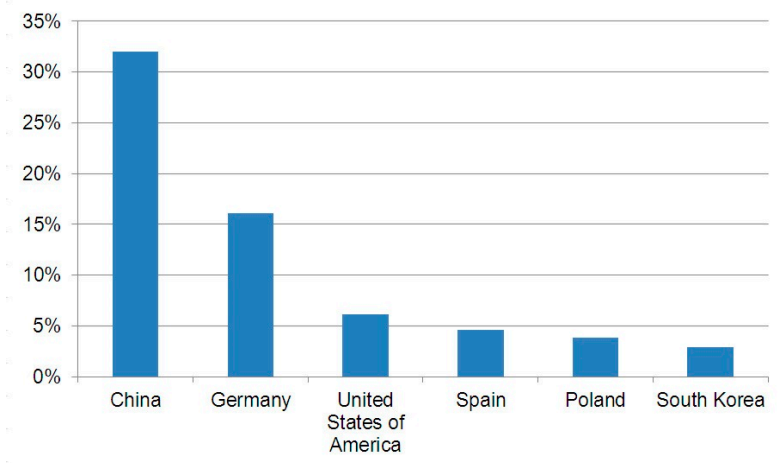

Figure 5. Distribution of publications between the top six countries.

The present survey puts the focus on the aforementioned types of scientific papers, nonetheless, a brief overview about OPC communication in patents also portrays the interest about this technology. A patent searching process was performed in the Scopus database applying the same query terms used for scientific contributions. For the time span 1996-2017, 1740 patents were found; their classification by year is shown in Figure 6. As it can be observed, the annual number of patents has not dropped from 100 since 2007, whilst the maximum number, 187 patents, was reached in 2017.

From all those publications, it was necessary to carry out manual filtering. Some of the contributions appear in the databases but are not available for downloading, so they have been discarded. A similar issue occurs with papers with English title and keywords but with the main text published in other language, in Chinese for example. In other cases, similarities between different papers have led to remove duplications. Another question is related to papers covering the usage of OPC classic in traditional automation networks. Only papers that also included some innovative concept (intelligent control for instance) were selected. 


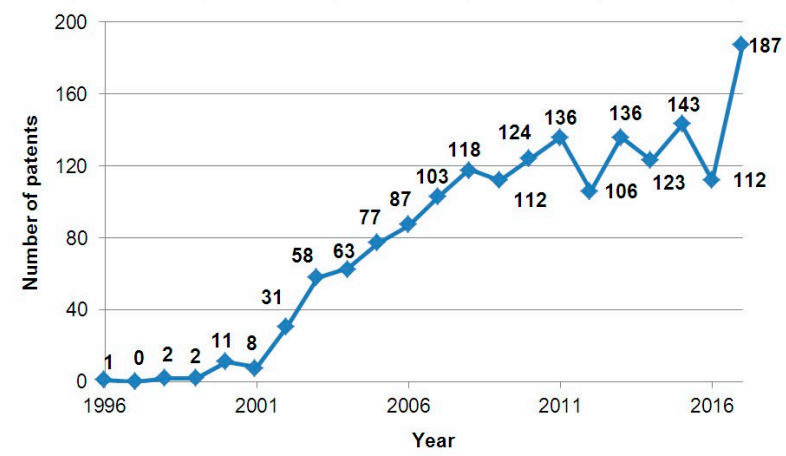

Figure 6. Number of patents per year from 1996 to 2017.

With the goal of identifying recent and relevant works, the search period was mainly focused on the last 10 years. Table 1 illustrates the distribution of the reviewed papers in the present work for these years. As can be seen, a total number of 158 articles, conference proceedings, and book chapters were surveyed. It should be noted that several of the surveyed papers do not give special prominence to the OPC interface but report successful application cases for different scopes. Therefore, they represent illustrative examples of the versatility and applicability of the OPC communication and have been included so that the survey is rigorous and comprehensive.

Table 1. Distribution of the reviewed papers during years.

\begin{tabular}{ccccccccccccccc}
\hline Year & 2017 & 2016 & 2015 & 2014 & 2013 & 2012 & 2011 & 2010 & 2009 & 2008 & 2006 & 2004 & 2002 & Total \\
\hline $\begin{array}{c}\text { No. } \\
\text { Publications }\end{array}$ & 19 & 45 & 31 & 16 & 15 & 10 & 9 & 5 & 4 & 1 & 1 & 1 & 1 & 158 \\
\hline
\end{tabular}

The classification of the literature was carried out taking into account the domain of application, distinguishing five scopes: industry, energy, education, and advanced industrial environments (AIEs). The last category groups those works devoted to the next generation of manufacturing and industrial facilities, significantly influenced by the modern trends of IoT, Industry 4.0, CPS, and big data, being the term AIEs conceived in the context of the present paper. We have preferred to consider them a category separated from the general industrial systems. Furthermore, another category, called others, includes those works that did not fit the first four groups, for instance devoted to precision agriculture, open source hardware (OSH) platforms, disaster management, or cyber-security. It should be noted that in many cases, the hardware and software elements are essentially the same, and the only difference is the field of application. Moreover, it must be kept in mind that the intelligent power grids, smart grids (SGs) are a particular kind of CPS applied to energy infrastructures. Nonetheless, we have preferred to include them into the energy scope. Figure 7 shows the distribution of the surveyed papers per scope. As can be seen, the AIEs group covers the highest percentage of contributions, namely, around $33 \%$.

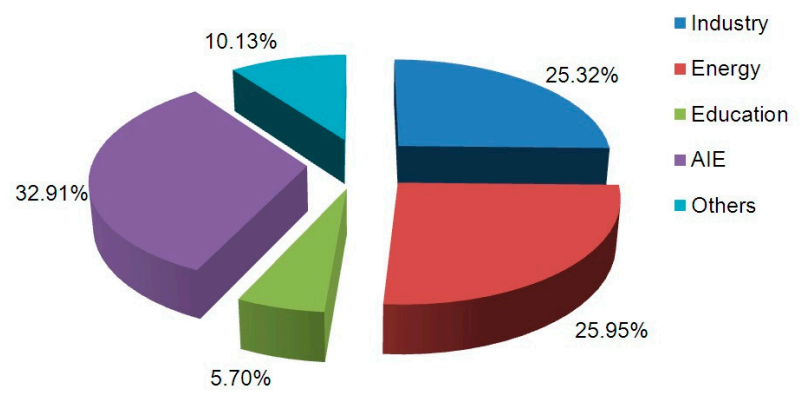

Figure 7. Distribution of reviewed papers per scope. 


\section{Results of Literature Survey}

In next sub-section, the surveyed literature is classified according to the established scopes and to the year, area, and country of publication. Afterwards, recent R\&D projects related to OPC applications are exposed.

\subsection{Classification}

For each scope, a set of subcategories was considered in order to group those works devoted to similar application cases. For instance, in the AIEs scope, three subcategories were addressed depending on the main focus of the papers: big data, CPPS-Industry 4.0 and integration of OPC UA with other protocols/languages.

In addition, it should be noted that, evidently, some of the works can be placed into more than one category. As a sample, the work reported by García et al. [32] deals with the CPPS concepts within the Industry 4.0 paradigm using low-cost OSH devices, so it could be allocated both in the AIEs and other scopes categories. However, in order to avoid duplicates, we have chosen a unique category for those situations. In the example case, it was considered as an AIEs application. Within the category others, a subcategory named particle physics infrastructures was considered to cover the publications related to facilities where advanced particle physics experiments were carried out, like the European Organization for Nuclear Research (CERN) [33] or the Reactor Experiment for Neutrino Oscillation (RENO) in South Korea [34].

Tables 2-6 collect the reference number of the surveyed works divided in the aforementioned group classification per scope. A consideration was related to websites about OPC UA packages for mobile devices [35,36], two references have been included in the table to illustrate the availability of such packages but not included in the graphical results since they are not published contributions.

Table 2. Publications in the category of industry.

\begin{tabular}{lcc}
\hline Category & Subcategory & Reference Number \\
\hline \multirow{3}{*}{ Industry } & Automation and supervision & {$[28,31,37-51]$} \\
& Advanced control algorithms & {$[52-66]$} \\
& Simulated and virtualized environments & {$[67-74]$} \\
\hline
\end{tabular}

Table 3. Publications in the category of energy.

\begin{tabular}{ccc}
\hline Category & Subcategory & Reference Number \\
\hline \multirow{4}{*}{ Energy } & Renewable energy-based facilities & {$[75-88]$} \\
& Smart grids and micro grids & {$[25,89-103]$} \\
& Building automation systems & {$[104-110]$} \\
& Other energy facilities & {$[111-114]$} \\
\hline
\end{tabular}

Table 4. Publications in the category of education.

\begin{tabular}{ccc}
\hline Category & Subcategory & Reference Number \\
\hline Education & - & {$[115-123]$} \\
\hline
\end{tabular}

Table 5. Publications in the category of advanced industrial environments (AIEs).

\begin{tabular}{ccc}
\hline Category & Subcategory & Reference Number \\
\hline \multirow{2}{*}{ AIEs } & Big data & {$[124-128]$} \\
& Cyber-physical production system (CPPS)-Industry 4.0 & {$[3-5,15,16,19,20,23,24,32,129-146]$} \\
& Open platform communications unified architecture (OPC UA) integrations & {$[147-166]$} \\
\hline
\end{tabular}


Table 6. Publications in the category of others.

\begin{tabular}{lcc}
\hline Category & Subcategory & Reference Number \\
\hline & Cyber security & {$[30,31,167-170]$} \\
Others & Moben source hardware (OSH) platforms & {$[171,172]$} \\
& Precision agriculture & {$[35,36]$} \\
& Emergency management & {$[173,174]$} \\
& Particle physics infrastructures & {$[175]$} \\
\hline
\end{tabular}

In order to illustrate the aforementioned categories, concrete examples of each will now be expounded. In the category industry, the work reported in reference [55] proposes an industrial artificial neural controller for recovery of faults in electrical distribution substations. Such controller results from the union between a PLC and a neural network (NN). The PLC performs operational tasks, whereas the $\mathrm{NN}$ algorithm performs data processing in MATLAB, being the information shared through an OPC-based communication channel. In the energy domain, representative research was found in References [100,101], where a hydrogen-based lab-scale microgrid to test different control strategies and their influence on the plant performance was presented. A central PLC receives all sensor signals and manages the actuators. On the other hand, a SCADA system implements advanced controllers through the MATLAB environment. The communication between these elements is performed through an OPC interface. Within the category education, OPC have been applied in reference [121] for a remote laboratory devoted to managing an electro-pneumatic flexible manufacturing system (FMS) composed of diverse equipment like robotic arms, conveyor belts, and pneumatic cylinders. A PLC controls the whole system and a PC runs supervisory software including an OPC server. The architecture relies on a LabVIEW-based middleware that communicates the measurements of the physical system and the commands sent by the remote user to a database through OPC. For the AIEs scope, Lee et al. [166] establish a mapping between OPC UA elements and UML elements. Specifically, a bi-directional transformation algorithm is developed and validated for three use cases, namely, building automation, power grid, and smart devices. Under the category others, in the context of precision agriculture, Oksanen et al. [173] demonstrate the feasibility of using OPC UA to transfer information of a mobile agricultural vehicle, i.e., a tractor. A data logger acquires the vehicle process data according to the ISO 11783 standard, whereas an OPC server makes those data available for the OPC client. Such a role is played by a management system which accesses remotely these data in real-time through a $3 \mathrm{G}$ mobile network.

A classification of the surveyed papers has been performed according to the criteria exposed in the previous section for the results of OPC-related works. Figure 8 shows the distribution of such papers from 2006 to 2016. As it can be seen, the higher amount of works, 45, corresponds to 2016. The division between the type of document is presented in Figure 9, where can be observed that around $65 \%$ of publications correspond to journal papers, $34 \%$ to congress contributions, and $1.42 \%$ correspond to book chapters. The distribution of papers among the top six subject areas is depicted in Figure 10, where engineering covers approximately $65 \%$ of contributions, followed by computer science with $49 \%$. Finally, the distribution between the top six countries can be appreciated in Figure 11 . Germany is the country with the largest percentage of these documents, $23 \%$, followed by Spain with $15 \%$. As commented in the previous section, $32 \%$ of the publications concerning OPC are generated in China; however, Germany leads the reviewed contributions due to the presence of two reasons. On the one hand, there are various R\&D initiatives about OPC UA in Germany; on the other hand, many of the Chinese contributions appear in databases but are not available in the English language. 


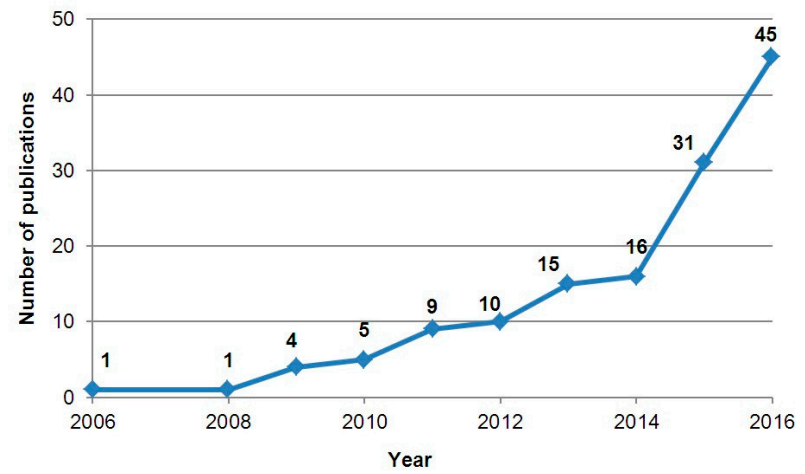

Figure 8. Number of surveyed publications per year from 2006 to 2016.

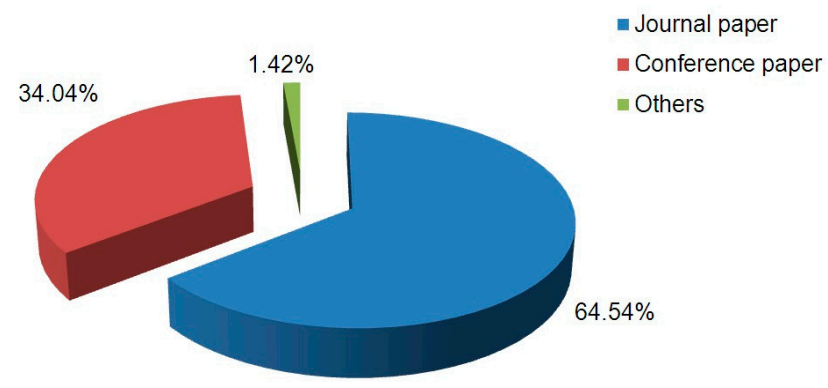

Figure 9. Distribution of surveyed papers according to their type.

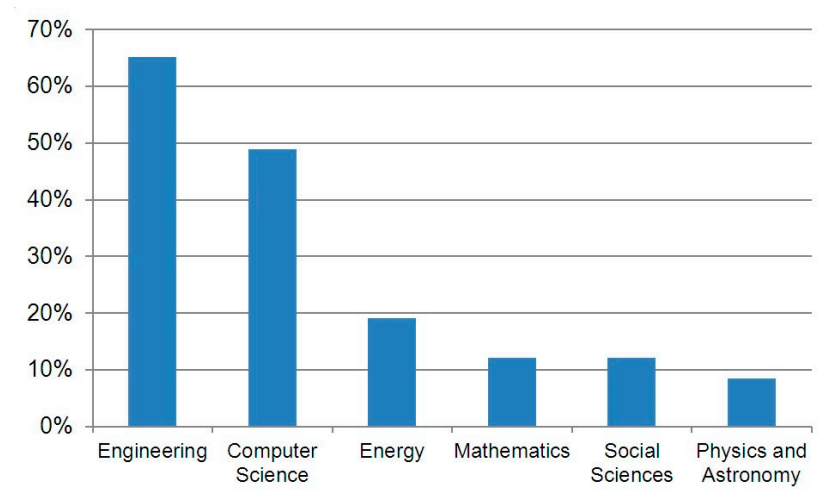

Figure 10. Distribution of surveyed publications between the top six subject areas.

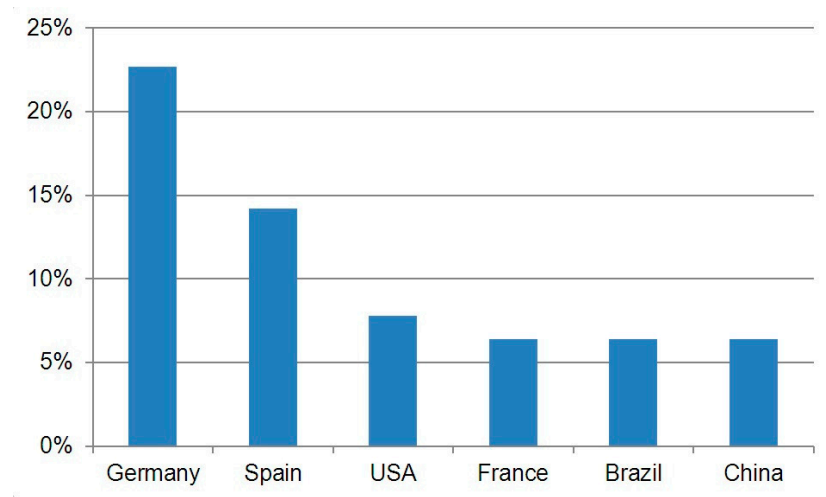

Figure 11. Distribution of surveyed publications between the top six countries. 


\subsection{RED Projects}

Nowadays, OPC UA, itself, is an object of study in various R\&D projects. In addition, both classic OPC and OPC UA act as communications means in different projects not directly devoted to OPC. Therefore, in this sub-section, a number of recent projects related with OPC are commented. These publicly funded, or partially funded, projects portray the interest from government institutions related to research towards technologies and frameworks where OPC is included.

The project entitled Information Modelling in Automation (IWT TETRA 110131) [179] started in 2012, and aimed to develop a methodology to exchange data, relevant to production in different types of industries, in a structured way. The relevant parts of industrial standards like International Society of Automation (ISA)-88 or ISA-95 were modelled using the modelling rules of OPC UA. Some paper related with this project have been published [130].

SkillPro [180] was a project started in 2012 and ended in 2015. The objective of the project was to bring smart reconfigurable manufacturing systems into application under the consideration that cyber-physical assets offer different skills. The composition and cooperation were based on the open standard of AutomationML (IEC 62714). The communication between the components was implemented using OPC UA, and the integration of both standards was also addressed. As a result of the project, the AutomationML for OPC UA companion specification was created and accepted.

The project Crop, Livestock and Forest Integrated System (CLAFIS) [181], started in 2013 and ended in 2016. It was intended to develop and demonstrate a pre-commercial intelligent integrated solution prototype. Such a prototype was based on the cross-platform OPC UA specification entitling standards and related technologies for communication between automation systems and IT systems in farms and forest related process. Some papers related with this project have been published $[173,174]$.

The objective of the project denominated Subject-Orientation for People-Centered Production (SO-PC-Pro) [182] was to develop methods and tools for holistic design and management of workplaces in production companies, thereby aligning business goals and human needs. The project started in 2013 and finished in 2016. As part of the project activities, OPC UA was used for implementing the interfaces between subject-oriented models and the specific control systems including human and environmental sensor data. Related with this project, an OPC UA interface was developed in reference [131] to provide data communication in a service-oriented business process management (S-BPM) system.

The OPC4Factory [183] was a project whose goal was to develop semantic OPC UA-based interfaces for robots and machine controllers of flexible automated manufacturing cells. In the context of the project, new objects and reference types for OPC UA were developed [153]. Integration with UML was also approached [160].

Another R\&D project, in this case related to SGs, is INGRID, high-capacity, hydrogen-based, green-energy storage solutions for grid balancing [184]. Started in 2012 and finished in 2016, the project aimed to introduce and demonstrate the usage of safe, high-density, solid-state hydrogen storage systems as an effective energy vector to balance the grid also by powering off-grid applications, thus enabling a smart balance between variable green energy sources supply and the grid demand. The experimental facility was composed of a water electrolyzer, fuel cell, and hydrogen solid storage units, managed by an energy management system. In this project, classic OPC was used as part of an intelligent monitoring, control, and communication solution to link the energy management system, a SCADA system, and the PLCs at field level [94].

The open62541 project [132] was initiated in 2014 and its objective was to develop an open reference implementation of the OPC UA which can be used in research projects, the source code can be downloaded from reference [185]. Other open source implementations are also under development such as FreeOpcUa [186] and OpenOpcUa [187].

A finished project is entitled Real-Time Monitoring and Optimization of Resource Efficiency in Integrated Processing Plants (MORE) [188]. The project aimed at identifying resource efficiency indicators that can support operational decisions in process industries through the use of real-time 
data and the implementation of a dedicated online decision support system. A classic OPC interface was used as part of the developed real-time communication approach.

The project Open Dynamic Manufacturing Operating System for Smart Plug-and-Produce Automation Components (openMOS) [189] started in 2015. The motivation of the project is for the European Manufacturing Industry to become increasingly agile in order to compete in the global economy. The project vision is to enable full economic sustainability of the production systems based on intelligent modular plug and produce equipment. Within the tasks of the project, plug and produce automation systems are being developed using OPC UA [145,165].

Production harmonizEd Reconfiguration of Flexible Robots and Machinery (PERFORM) is the name of a project started in 2015. The project target is the conceptual transformation of existing production systems towards plug and produce production systems in order to achieve a flexible manufacturing environment based on rapid and seamless reconfiguration of machinery and robots as a response to operational or business events, including OPC UA as middleware [190].

Out of R\&D projects, some work is in progress. The PLCOpen organization is also working with the OPC Foundation to develop IEC 61131 Function Blocks providing OPC UA client functionality [148,191]. In 2013, the MTConnect Institute and the OPC Foundation announced a companion specification release candidate that integrates the MTConnect standard and OPC UA [192]. In April 2016, the OPC Foundation and the World Wide Web Consortium (W3C) have agreed to closely cooperate to ensure interoperability for the IoT and to facilitate the vision and execution of a Smart Factory [193]. The addition of the publish/subscribe messaging pattern to the OPC UA specifications has been lately released, in March 2018 [194]. This support is intended to achieve seamless interoperability for industrial IoT (IIoT), IoT, and Industry 4.0 enhancing the integration with modern cloud platforms.

Concerning enterprises, there are numerous corporate innovation programs related to Industry 4.0/IIoT already available, which include OPC UA. For instance, the Connected Industry from Bosch [195] provides software suites like the Nexeed Connected Manufacturing solutions or the Rexroth IoT Gateway. Schneider Electric has developed the EcoStruxure, an IoT-enabled architecture and platform [196]. Digital Enterprise is the approach of Siemens towards Industry 4.0 [197], which, among other solutions, offers MindSphere, a cloud-based, open IoT operating system. Other examples correspond to the Connected Enterprise program of Rockwell Automation [198] or the Connected Factory of Microsoft [199].

\section{Discussion}

This section discusses the major findings of the conducted literature survey. The first sub-section is devoted to analyzing the components most profusely reported in the OT level, i.e., hardware devices, and in the IT level, this latter was focused on supervisory software. The sub-Section 4.2 deals with the role that OPC UA is playing in AIEs. Lastly, the main research trends and open issues about OPC UA developments are addressed.

\subsection{Software and Hardware Entities}

On the view of the state-of-the-art, the following figures are intended to illustrate the software packages and devices used for OPC-based communications in the reviewed works. However, it should be remarked that many of the papers do not specify such information, thus, obviously, the graphical information was fulfilled according to the available data. Specifically, the OPC client software was mentioned in $32 \%$ of papers, the OPC server software in $22 \%$, and $40 \%$ indicated the hardware apparatus that was applied.

Figure 12a shows the OPC client packages (IT level) reported where the most used one was National Instruments (NI) LabVIEW (32.65\%), closely followed by MATLAB (30.61\%). In the case of OPC server, Figure 12b, the environment NI OPC Servers was mainly used with a presence of $23.5 \%$, whilst WinCC occupied second place with $17.65 \%$. As can be seen, within the wide variety of 
implementations, the proprietary packages were clearly dominant. In the authors' opinion, this was due to two main reasons. The first one was that commonly the person responsible for systems integration lacks the specialized expertise for low-level configuration required by open source solutions. The second reason was related to the proven stability and support that commercial packages provide.

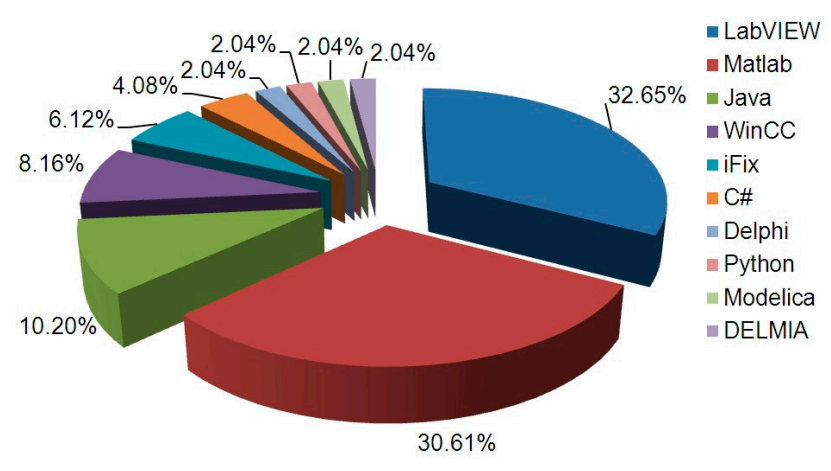

(a)

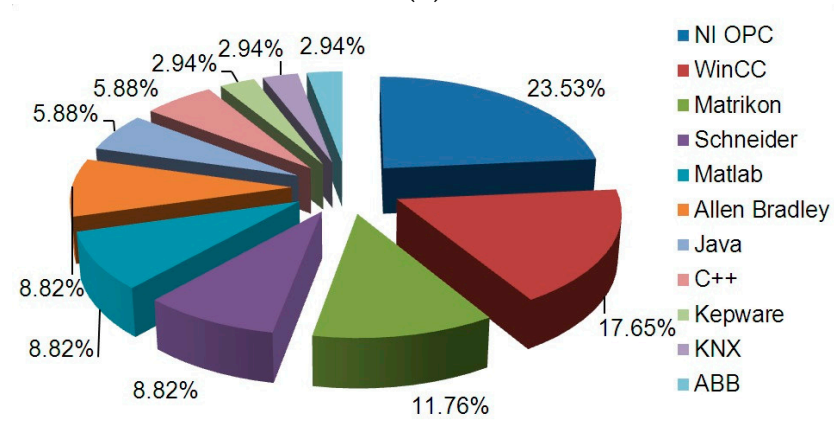

(b)

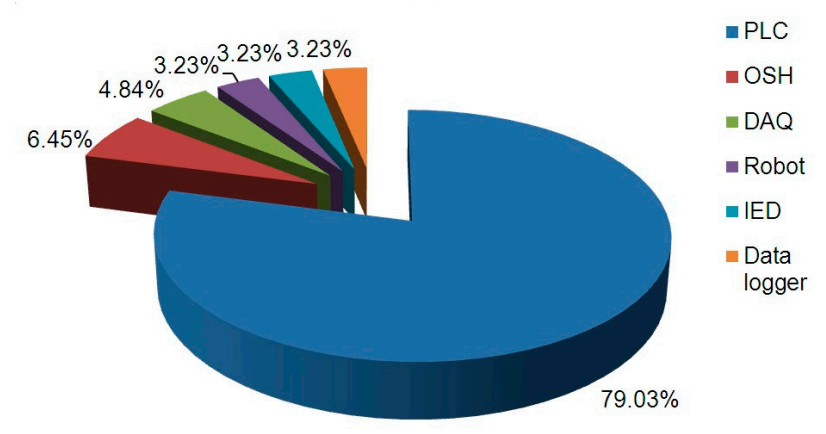

(c)

Figure 12. Overview of the software and hardware entities used by the reviewed works: (a) OPC client software; (b) OPC server software; (c) Hardware devices.

Concerning the hardware equipment (OT level), as expected, PLCs were mostly used; $79 \%$ of the reported works manage these devices (Figure 12c). The OSH platforms (Arduino, Raspberry Pi) received increasing attention, mainly in the academic environment because of their low-cost and rapid prototyping features.

Concerning the communications approaches, Table 7 summarizes the utilization of OPC jointly with different communication fieldbuses, protocols, and languages in the surveyed works.

Table 8 contains the reviewed works divided according to the covered specification, classic OPC or OPC UA. The publications that cover both or do not indicate the specification were put in a separate 
group; there was a total number of nine works (5.73\%) in this situation; $54.77 \%$ of publications use the classic OPC, whereas $39.49 \%$ deal with OPC UA.

Table 7. Communication fieldbuses, protocols, and languages used with OPC.

\begin{tabular}{cc}
\hline Fieldbus/Protocol & Reference \\
\hline PROcess FIeld Bus (PROFIBUS) & {$[60,77,78,92,151]$} \\
MODBUS & {$[107,109]$} \\
Controller Area Network (CAN) & {$[33,77,78]$} \\
Local Operating Network (LON) & {$[86,104,149]$} \\
Ethernet for Control of Automation Technology (EtherCAT) & {$[95]$} \\
Building Automation and Control Networks (BACnet) & {$[109,149,175]$} \\
Smar Foundation & {$[37]$} \\
International Electrotechnical Commission (IEC) 61850 & {$[152,156,163,164]$} \\
Distributed Network Protocol (DNP3) & {$[97]$} \\
Common Information Model (CIM) & {$[159]$} \\
Unified Modelling Language (UML) & {$[150,160,166]$} \\
Devices Profiles for Web Services (DPWS) & {$[147,152]$} \\
Automation Markup Language (AutomationML) & {$[154,165]$} \\
Robot Modelling Language (RobotML) & {$[155]$} \\
Representational State Transfer (REST) & {$[157]$} \\
KNX & {$[90,149]$} \\
ZigBee & {$[149,171]$} \\
MTConnect & {$[16]$} \\
Data Distribution Service (DDS) & {$[161]$} \\
International Society of Automation (ISA) 95 & {$[15]$} \\
\hline
\end{tabular}

Table 8. Reviewed publications grouped according to the utilization of classic OPC, OPC UA or both.

\begin{tabular}{cc}
\hline Specification & Reference \\
\hline Classic OPC & {$[24,31,34,37-47,49-68,70-88,90,92-94,98,100-102,104-107,110-122,125-127,167,170,171,178]$} \\
OPC UA & {$[3-5,15,16,19,20,23,28,30,32,33,48,69,91,95,99,109,123,128,130-133,135-166,168,169,172-174,176]$} \\
Both or undetermined & {$[25,29,89,96,108,124,129,134,177]$} \\
\hline
\end{tabular}

In a similar sense, Figure 13 shows the specification used in the surveyed works, classic OPC or OPC UA, over time. Those publications reporting both specifications were not included for a clearer presentation. In most cases, when using classic OPC, it was not explicitly mentioned whereas the UA usage was highlighted. The starting year was 2010, since it corresponds to the first of the reviewed works addressing UA utilization. As it can be appreciated, in global terms, classic OPC was mostly used but with a small difference; around $49 \%$ of contributions used this specification, whereas $40 \%$ dealt with UA. It is worth mentioning that the classic OPC was still applied despite the increasing interest about UA. In the last two years, the trend was inverted; the amount of papers related to UA exceeded that dedicated to classic OPC.

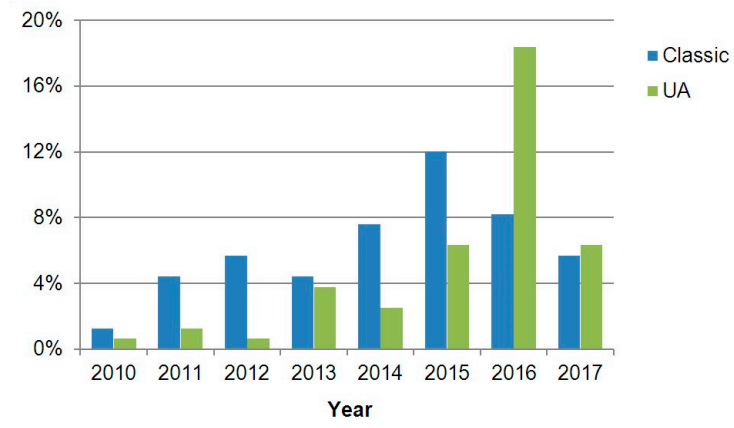

Figure 13. Distribution of the OPC specification usage in the reviewed contributions over time. 


\subsection{Role of OPC UA in AIEs}

This sub-section contains some considerations about the interplay of OPC UA and the modern challenging scenarios drawn from this literature review.

The great number of recent works reporting applications of classic OPC shows that this protocol is noticeably still under exploitation so it must be taken into account in the deployment of AIEs. In other words, despite the fact that the UA specification is the core of the majority of developments related to AIEs, the classic OPC still remains in the cutting edge of advanced systems design.

Regarding R\&D projects, it has been stated that OPC UA is used to support communications and interoperability in a number of recent projects dealing with advanced topics, mainly related to automation and energy.

In the Industry 4.0 scenario, the embedding of OPC UA into industrial environments is a first step towards the goals of this paradigm [142]. In fact, OPC UA is explicitly considered as a key technology to manage heterogeneous machine interoperability [155], addressing the challenges derived from this new framework $[139,142]$. Indeed, the RAMI 4.0 mentions OPC UA as a recommended communication technology [21].

The UA specification is a major contender for the application protocol which will be used in the domain of CPS [157]. For manufacturing environments, it is expected to play an important role in the CPPS development as language for standardization of communications in a machine-to-machine (M2M) context [134], providing a reliable, robust and high-performance communication means [32], and connecting and transmitting information between different CPPSs [23]. In the context of implementing digital replicas of physical systems/processes, OPC UA was also reported as communication interface for data exchange in $[123,124,143,144,160]$.

Diverse advanced approaches like virtual and cloud manufacturing, data-driven decision support, predictive manufacturing, prognostics and health management (PHM), self-organizing maps, to name a few, are based on data acquisition, storage, and processing, where the interoperability management is an essential issue. In this sense, an important trend consists on the exploitation of OPC UA to collect operative information and generate industrial big data and cloud computing, where big data analytics could bring several advantages when applied to manufacturing domain [2]. Industrial big data is of high importance for an enterprise, as this data can be used and analyzed to provide meaningful information making them adaptive and flexible [128].

Concerning IoT, UA is considered safe and secure communication for IoT devices [174], to empower the interfacing with existing information technology tools in IIoT environments [128], and as an information carrier for IoT and next generation industrial communications [140].

In the energy automation sphere, despite the definition of communication standards focused on electric utilities like the IEC 61850, IEC 61970 or DNP3, OPC is profusely used for grids and noticeably for SGs [24], where OPC UA is signaled as one of the fundamental standards for automation and communications [150].

Communication standardization attempts in automation are primarily focused on interfaces like classic OPC. However, the aggregation of data created by field devices (sensors or control units) into useful information remains still unsolved as their underlying models are carried out using different modeling paradigms and programming languages [139]. In this regard, a special mention must be done for OPC UA specification. Thanks to the information model and the address space, this specification has a great potential, and is in fact, expanding the application possibilities of OPC. The object-oriented approach of UA allows defining custom or domain-specific information models that extend the base information model and make OPC UA specialized for various domains [153]. An important research stream is devoted to integrating existing data models and protocols by mapping them to OPC UA.

To sum up with a wider perspective, since its inception, OPC interfaces have been a step forward in the interconnectivity in automation and supervisory systems. The conducted literature survey evidences that it is still gaining relevance in current applications, mainly the OPC UA. Furthermore, on the one hand, this protocol evolves through the improvements of its specifications, and on 
the other hand, it is being used in diverse applications which involve the most modern trends in technology. All of the exposed advanced scenarios share a common backbone: reliable and effective information communication with interoperability and open connectivity features. As demonstrated, OPC UA successfully supports such features. The interplay of OPC UA with the abovementioned challenges is symbolized in Figure 14.

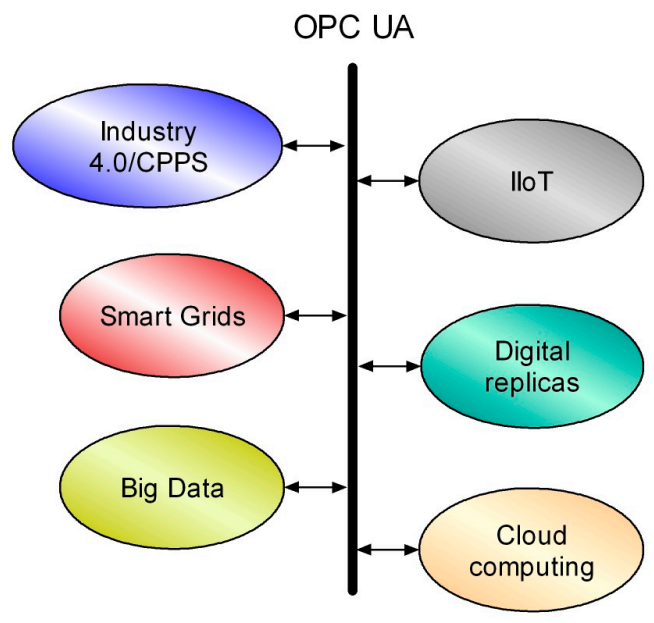

Figure 14. Interplay of OPC unified architecture (UA) in the challenges.

\subsection{Trends and Open Research Issues}

As is evident, the classic OPC is still considered in already existing systems and also in designing new facilities. However, it has been proved that the most promising specification is the last one, UA, which is a prolific field of R\&D activities. In fact, old OPC is not developed any more. Consequently, the main trends are towards the improvements and applications of that specification. The open research issues observed after the performed survey are now expounded, being summarized in Figure 15.

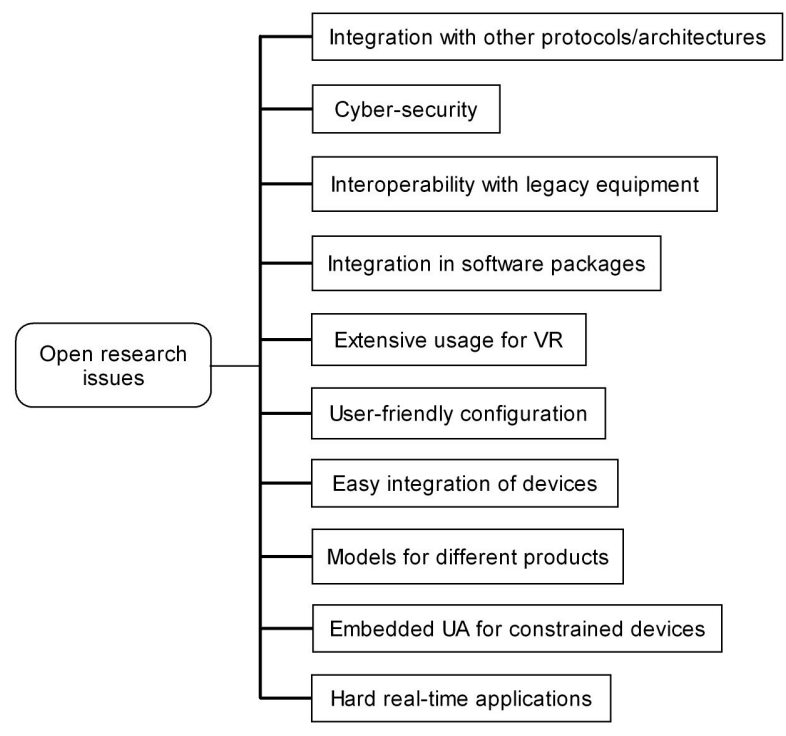

Figure 15. Scheme of the identified open research issues.

- Integration of OPC UA with other protocols or software architectures in domains like SGs and CPPSs. The standards and languages that are being integrated are protocols for building automation systems (KNX, BACnet, LonWorks) [149], UML [150,160,166], IEC 61131 [148], 
IEC 61499 [158], DPWS [147,152], IEC 61850 [152,156,163,164], AutomationML [154,165], RobotML [155], CIM [159], DDS [161], REST [157], ISA 95 [15], and open-source middleware platform for IoT devices (OpenIoT) [141]. Once validated, the standardization of the developed integrating extensions/models should be achieved by submitting them to the OPC Foundation. However, the modelling of domain-specific information into OPC UA meta-models is still lacking a uniform formalization of ontology-represented knowledge [142]. Consequently, this issue will receive important research attention.

- Cyber-security issues in OPC UA. Data communication networks are vulnerable to cyber-attacks and malware; thus, aspects like confidentiality, integrity, availability, reliability, and safety of the process are under real risk. The UA specification enhances the security features of the previous ones including user authentication, user authorization, confidentiality, integrity and application authentication [29]. Indeed, in many industrial projects the security concept is often the decisive factor for the usage of this technology [154]. Utilization of standard protocols for SCADA communication networks is a potential security breach because detailed information about the protocol is available for anyone interested, reducing the security through obscurity [167]. Recently, the German Office for Information Security (BSI) performed an analysis of OPC UA security features and identified various flaws that are planned to be solved [200]. Therefore, the ever-increasing threat of cyber-attacks imposes research efforts devoted to this topic, mainly towards the enhancement of the security mechanisms of this specification $[30,168,169]$.

- Interoperability with legacy equipment. In the emerging and challenging new paradigms, OPC UA can play a relevant role in managing the obsolescence of equipment by enabling the communication between new devices and older reliable infrastructures. A problem that arises in this context is that most enterprises refuse a radical modernization of their entire automation system or simply cannot take the risk of quitting a running system [201]. Industry 4.0 is envisioned to facilitate inter-connection and computerization into the traditional industry [18]; however, the current situation in production organization is still lacking profound interoperability in terms of vertical information exchange [142]. Consequently, to enable scenarios of the Industry 4.0 in existing production sites; a true challenge is to extend capabilities of the hardware infrastructure that is in use to implement modern ways of information management [139]. OPC UA can promote the integration of existing production systems in the CPPS framework [133]. However, many PLCs' firmware does not support OPC UA advanced communication features [20] and OPC UA is not directly backward compatible with classic OPC, so interfaces for both are required. To tackle this issue, there are commercial solutions that facilitate the migration process or the co-existence of classic and recent releases of OPC. Also, some research efforts are being conducted towards developing compatible frameworks [139] and open source solutions based on OPC UA [15]. Enabling full interoperability between these protocols represents a research opportunity with significant relevance in real industrial practice.

- Integration of UA specification in software packages for advanced simulation. The usage of OPC for simulated environments has been reported in Section 3. Although, as the OPC UA is gaining importance and replacing previous specifications, there is still the need of including software modules that support such specification [71]. Hence, labor must be done in this direction.

- Extensive usage of OPC UA for virtual reality (VR) applications. At the industrial level, VR provides powerful resources for designing and scheduling of manufacturing environments considering issues related to automation, maintenance, ergonomics, security, mobile robots, industrial training, technical education, remote collaboration, and many others. In addition, advancements in virtual and augmented reality are envisioned to enhance the interactivity between the human operators and CPS [202]. In 2016, various VR headsets (Oculus Rift, HTC Vive) have been released at the consumer-level in the market, so the number of VR applications is expected to increase due to the impact of these devices. 
- User-friendly configuration. High technical expertise is required to adjust many critical parameters of OPC UA [28]; great effort has to be spent on building the application-specific information models, which usually makes the implementation of OPC UA complex and inefficient $[142,144]$. Thus, it is necessary to design software interfaces with user-friendly features to facilitate the configuration and tracking of the OPC UA-related operations. This issue would provide an excellent opportunity to foster and spread its utilization even with training and educational purposes.

- Easy integration of devices. Intimately related to the previously commented research issue, an important step towards a real standardization of communications is a common interface that facilitates the direct connection of new devices (sensor, actuator, controller, etc.) into an existing system. Embedded OPC UA interfaces in new generations of machinery and robots will enable direct connection to the process [143]. The development of the plug and produce concept, or plug and work, using OPC UA $[3,20,145]$ reflects this necessity. Moreover, to reach such an approach, the manufacturers must collaborate, agreeing to the adoption of the OPC UA interface.

- OPC UA models for different products of manufacturers. The creation of these models will facilitate the application of such a protocol in their specific domains. Consequently, the availability of models will encourage and expand the presence of OPC UA. In this regard, similar to the precedent trend, the collaboration among the OPC Foundation and companies is an essential factor.

- On-chip embedded OPC UA for resource constrained devices. In the context of the IoT/IIoT, the number of connected devices is constantly increasing, and especially resource constrained devices required to be efficiently linked. Lightweight communication protocols like MQTT or constrained application protocol (CoAP) are precisely designed for this kind of device. However, advancements in OPC UA are also promoting its application in this stimulating field. New implementations with low computational requirements are even commercially available [203]. The use of ever-smaller embedded chips that integrate OPC UA allows making further in-roads into the world of sensors [204]. This way, smart sensors with limited capabilities can be provided with native OPC UA connectivity to be deployed at the shop floor level, enhancing the applicability of OPC UA.

- Hard real-time applications. OPC UA presents a lack of hard real-time capabilities [4]. However, some research is being conducted to develop a specification using the IEEE 802.1 standard for time sensitive networking (TSN), enlarging the possibilities of OPC UA and simplifying many applications in industry and research [141]. The so-called OPC UA TSN is expected to enable implementing a single Ethernet network where both real-time and non-real-time data are transmitted. The OPC UA publish/subscribe extension (PubSub) which also contributes to the development of such deterministic data exchange [194]. These advances boost the deployment of IIoT and Industry 4.0 frameworks.

\section{Conclusions}

This paper has presented a comprehensive literature survey about the use of the OPC interface (both classic and UA) in a number of domains by examining existing publications, mainly contributions from scientific journals and conferences. From the total amount of 866 publications found in the literature up to the year 2017, 158 papers were selected and surveyed. These contributions were grouped into five categories and analyzed. This standard provides an effective solution to handle the heterogeneity, enabling interoperability and systems integration regardless of the nature of the hardware/software component. The reviewed works showed that OPC goes far beyond the industrial automation domain and is applied for widely diverse scopes (energy, education, etc.). In addition, recent R\&D projects and initiatives involving OPC have been exposed. It is worth noting that apart from research efforts from academia, industrial enterprises also contribute significantly to extend and improve the applications of OPC UA in the incoming advanced frameworks. Special attention has been put on the so-called advanced industrial environments (AIEs) that constitute the next generation of industrial systems under the frameworks of new innovative scenarios like Industry 4.0, IoT, and CPS. 
Current main trends and open research directions have been outlined as well. We have highlighted that the UA specification is receiving growing attention in order to take advantage of its abilities by means of improvements and integration with other languages and protocols. Particularly, this specification has proven to be an essential element in the context of CPS and Industry 4.0. Further standardization work is required both from industrial and scientific environments. We can assert that this protocol is playing an important role in those challenging scenarios.

Researchers, academicians, and practitioners can stay up to date with the latest works on OPC and find useful ideas among them. Notwithstanding of the particular application area, this research encourages the utilization of OPC UA to handle systems integration and interoperability when designing AIEs.

Author Contributions: Conceptualization, I.G., A.J.C. and J.F.; Methodology, I.G. and J.M.C.S.; Validation, I.G., A.J.C. and J.F.; Investigation, I.G., A.J.C. and J.F.; Data Curation, A.J.C. and J.F.; Writing-Original Draft Preparation, I.G.; Writing-Review and Editing, I.G., A.J.C., J.F. and J.M.C.S.; Supervision, J.F. and J.M.C.S.

Funding: This research has been funded by the project IB18041 supported by the Junta de Extremadura in the VI Plan Regional de I+D+i (2017-2020), co-financed by the European Regional Development Funds FEDER (Programa Operativo FEDER de Extremadura 2014-2020).

Acknowledgments: In a self-criticism exercise, given the large amount of OPC-related publications, the authors would like to apologize for those contributions that could have been left unnoticed.

Conflicts of Interest: The authors declare no conflict of interest.

\section{Abbreviations}

The following abbreviations are used in this manuscript:

$\begin{array}{ll}\text { AIEs } & \text { Advanced Industrial Environments } \\ \text { AutomationML } & \text { Automation Markup Language } \\ \text { BACnet } & \text { Building Automation and Control Networks } \\ \text { CAN } & \text { Controller Area Network } \\ \text { CERN } & \text { European Organization for Nuclear Research } \\ \text { CIM } & \text { Common Information Model } \\ \text { CoAP } & \text { Constrained Application Protocol } \\ \text { CPPS } & \text { Cyber-Physical Production System } \\ \text { DAQ } & \text { Data Acquisition Card } \\ \text { DDS } & \text { Data Distribution Service } \\ \text { DNP3 } & \text { Distributed Network Protocol } \\ \text { DPWS } & \text { Devices Profiles for Web Services } \\ \text { EMS } & \text { Manufacturing Execution System } \\ \text { ERP } & \text { Enterprise Resource Planning } \\ \text { EtherCAT } & \text { Ethernet for Control of Automation Technology } \\ \text { FMS } & \text { Flexible Manufacturing System } \\ \text { GUI } & \text { Graphical User Interface } \\ \text { HMI } & \text { Human Machine Interface } \\ \text { ICPS } & \text { Industrial Cyber-Physical Systems } \\ \text { ICTs } & \text { Information and Communication Technologies } \\ \text { IEC } & \text { International Electrotechnical Commission } \\ \text { IEEE } & \text { Institute of Electrical and Electronics Engineers } \\ \text { IIRA } & \text { Industrial Internet Reference Architecture } \\ \text { IED } & \text { Intelligent Electronic Device } \\ \text { IoE } & \text { Internet of Everything } \\ \text { IoT } & \text { Internet of Things } \\ \text { ISA } & \text { International Society of Automation } \\ \text { IT } & \text { Information Technology } \\ \text { LON } & \text { Local Operating Network } \\ \text { M2M } & \text { Machine to Machine } \\ & \end{array}$




$\begin{array}{ll}\text { MQTT } & \text { Message Queue Telemetry Transport } \\ \text { NN } & \text { Neural Network } \\ \text { NI } & \text { National Instruments } \\ \text { OPC } & \text { Open Platform Communications } \\ \text { OPC A\&E } & \text { OPC Alarms and Events } \\ \text { OPC CD } & \text { OPC Complex Data } \\ \text { OPC DA } & \text { OPC Data Access } \\ \text { OPC DX } & \text { OPC Data eXchange } \\ \text { OPC HDA } & \text { OPC Historical Data Access } \\ \text { OPC UA } & \text { OPC Unified Architecture } \\ \text { OPC Xi } & \text { OPC Express Interface } \\ \text { OPC XML-DA } & \text { OPC XML Data Access } \\ \text { OT } & \text { Operative Technology } \\ \text { PHM } & \text { Prognostics and Health Management } \\ \text { PLC } & \text { Programmable Logic Controller } \\ \text { PROFIBUS } & \text { PROcess Fleld Bus } \\ \text { RENO } & \text { Reactor Experiment for Neutrino Oscillation } \\ \text { RES } & \text { Renewable Energy Sources } \\ \text { REST } & \text { Representational State Transfer } \\ \text { RFID } & \text { Radio Frequency IDentification } \\ \text { RobotML } & \text { Robot Modelling Language } \\ \text { S-BPM } & \text { Service-Oriented Business Process Management } \\ \text { SCADA } & \text { Supervisory Control and Data Acquisition } \\ \text { SOA } & \text { Service Oriented Architecture } \\ \text { UML } & \text { Unified Modeling Language } \\ \text { VR } & \text { Virtual Reality } \\ \text { WSN } & \text { Wireless Sensor Network }\end{array}$

\section{References}

1. Leitão, P.; Rodrigues, N.; Barbosa, J.; Turrin, C.; Pagani, A. Intelligent products: The grace experience. Control Eng. Pract. 2015, 42, 95-105. [CrossRef]

2. Babiceanu, R.F.; Seker, R. Big Data and virtualization for manufacturing cyber-physical systems: A survey on the current status and future work. Comput. Ind. 2016, 81, 128-137. [CrossRef]

3. Monostori, L.; Kádár, B.; Bauernhansl, T.; Kondoh, S.; Kumara, S.; Reinhart, G.; Sauer, O.; Schuh, G.; Sihn, W.; Ueda, K. Cyber-physical systems in manufacturing. CIRP Ann. Manuf. Technol. 2016, 65, 621-641. [CrossRef]

4. Ismail, A.; Kastner, W. A middleware architecture for vertical integration. In Proceedings of the 1st International Workshop on Cyber Physical Production Systems (CPPS), Vienna, Austria, 12 April 2016. [CrossRef]

5. Riedl, M.; Zipper, H.; Meier, M.; Diedrich, C. Cyber-physical systems alter automation architectures. Annu. Rev. Control 2014, 38, 123-133. [CrossRef]

6. Colombo, A.W.; Karnouskos, S.; Shi, S.; Yin, Y.; Kaynak, O. Industrial Cyber-Physical Systems. Scanning the Issue. Proc. IEEE 2016, 104, 899-903. [CrossRef]

7. Leitão, P.; Colombo, A.W.; Karnouskos, S. Industrial automation based on cyber-physical systems technologies: Prototype implementations and challenges. Comput. Ind. 2016, 81, 11-25. [CrossRef]

8. Colombo, A.W.; Karnouskos, S.; Kaynak, O.; Shi, Y.; Yin, S. Industrial Cyberphysical Systems. A Backbone of the Fourth Industrial Revolution. IEEE Ind. Electron. Mag. 2017, 11, 6-16. [CrossRef]

9. Platform Industrie 4.0 Webpage. Available online: http://www.plattform-i40.de/I40/Navigation/EN/Home/ home.html (accessed on 28 January 2019).

10. La Nouvelle France Industrielle Webpage. Available online: http://www.gouvernement.fr/action/la-nouvellefrance-industrielle (accessed on 28 January 2019).

11. Program Industria Conectada Webpage. Available online: http://www.industriaconectada40.gob.es/Paginas/ Index.aspx\# (accessed on 28 January 2019). 
12. Made in China 2025 Strategy to Drive Economic Transformation. Available online: http://english.gov.cn/ news/top_news/2017/04/16/content_281475628095631.htm (accessed on 28 January 2019).

13. Smart Manufacturing Leadership Coalition webpage. Available online: https://www.smartmanufacturingcoalition.org/ (accessed on 28 January 2019).

14. Robot Revolution and Industrial IoT Initiative webpage. Available online: https://www.jmfrri.gr.jp/english/ (accessed on 28 January 2019).

15. Givehchi, O.; Landsdorf, K.; Simoens, P.; Colombo, A.W. Interoperability for industrial cyber-physical systems: An approach for legacy systems. IEEE Trans. Ind. Inform. 2017, 13, 3370-3378. [CrossRef]

16. Oliveira, L.E.S.; Álvares, A.J. Axiomatic design applied to the development of a system for monitoring and teleoperation of a CNC machine through the internet. Procedia CIRP 2016, 53, 198-205. [CrossRef]

17. Botta, A.; de Donato, W.; Persico, V.; Pescapé, A. Integration of Cloud computing and Internet of Things: A survey. Future Gener. Comput. Syst. 2016, 56, 684-700. [CrossRef]

18. Lu, Y. Industry 4.0: A survey on technologies, applications and open research issues. J. Ind. Inf. Integr. 2017, 6, 1-10. [CrossRef]

19. Pauker, F.; Ayatollahi, I.; Kittl, B. OPC UA for machine tending industrial robots. In Proceedings of the 2nd International Conference on Advances in Mechanical and Robotics Engineering (AMRE), Zurich, Switzerland, 25-26 October 2014. [CrossRef]

20. Weyer, S.; Schmitt, M.; Ohmer, M.; Gorecky, D. Towards Industry 4.0-Standardization as the crucial challenge for highly modular, multi-vendor production systems. IFAC-PapersOnLine 2015, 48, 579-584. [CrossRef]

21. ZVEI - Industrie 4.0 News, Reference Architectural Model RAMI 4.0. Available online: https://www.zvei. org/en/subjects/industry-4-0/the-reference-architectural-model-rami-40-and-the-industrie-40-component/ (accessed on 29 January 2019).

22. Industrial Internet Consortium-Industrial Internet Reference Architecture webpage. Available online: http://www.iiconsortium.org/IIRA.htm (accessed on 29 January 2019).

23. Hehenberger, P.; Vogel-Heuser, B.; Bradley, D.; Eynard, B.; Tomiyama, T.; Achiche, S. Design, modelling, simulation and integration of cyber physical systems: Methods and applications. Comput. Ind. 2016, 82, 273-289. [CrossRef]

24. González, I.; Calderón, A.J.; Barragán, A.J.; Andújar, J.M. Integration of Sensors, Controllers and Instruments Using a Novel OPC Architecture. Sensors 2017, 17, 1512. [CrossRef]

25. Ziogou, C.; Voutetakis, S.; Papadapoulou, S. Design of an energy decision framework for an autonomous RES-enabled Smart-Grid network. In Proceedings of the 23rd International Conference on Telecommunications (ICT), Thessaloniki, Greece, 16-18 May 2016. [CrossRef]

26. Van der Kanijff, R.M. Controls systems/SCADA forensics, what's the difference? Digit. Investig. 2014, 11, $160-174$. [CrossRef]

27. OPC Foundation webpage. Available online: https://opcfoundation.org/ (accessed on 29 January 2019).

28. Cavalieri, S.; Chiacchio, F. Analysis of OPC UA performances. Comput. Stand. Interfaces 2013, 36, $165-177$. [CrossRef]

29. Schwarz, M.H.; Börcsök, J. A survey on OPC and OPC-UA. In Proceedings of the XXIV International Conference on Information, Communication and Automation Technologies (ICAT), Sarajevo, Bosnia and Herzegovina, 30 October-1 November 2013. [CrossRef]

30. Puys, M.; Potet, M.L.; Lafourcade, P. Formal analysis of security properties on the OPC-UA SCADA protocol. In Proceedings of the 35th International Conference on Computer Safety, Reliability, and Security (SAFECOMP), Trondheim, Norway, 21-23 September 2016. [CrossRef]

31. Holley, D.W. Understanding and using OPC maintenance and reliability applications. Comput. Control Eng. J. 2004, 15, 28-31. [CrossRef]

32. García, M.V.; Pérez, F.; Calvo, I.; Moran, G. Developing CPPS within IEC-61499 based on low cost devices. In Proceedings of the IEEE World Conference on Factory Communication Systems (WFCS), Palma de Mallorca, Spain, 27-29 May 2015. [CrossRef]

33. Nikiel, P.; Farnham, B.; Franz, S.; Schlenker, S.; Boterenbrood, H.; Filimonov, V. OPC unified architecture within the control system of the ATLAS experiment. In Proceedings of the 14th International Conference on Accelerator \& Large Experimental Physics Control Systems, ICALEPCS 2013, San Francisco, CA, USA, 6-11 October 2013. 
34. Choi, J.H.; Jang, H.I.; Choi, W.Q.; Choi, Y.; Jang, J.S.; Jeon, E.J.; Joo, K.K.; Kim, B.R.; Kim, H.S.; Kim, J.Y.; et al. Slow control systems of the Reactor Experiment for Neutrino Oscillation. Nucl. Instrum. Methods Phys. Res. Sect. A Accel. Spectrometersdetectors Assoc. Equip. 2016, 810, 100-106. [CrossRef]

35. GitHub webpage about OPC UA Client on Android. Available online: https://github.com/TommyR22/ Android-OPC_Client (accessed on 29 January 2019).

36. Prosys products, OPC UA Client for Android. Available online: https://www.prosysopc.com/products/opcua-client-for-android/ (accessed on 29 January 2019).

37. Fadaei, A.; Salahshoor, K. Design and implementation of a new PID controller for networked control systems. ISA Trans. 2008, 47, 351-361. [CrossRef]

38. Sahin, C.; Bolat, E.D. Development of remote control and monitoring of web-based distributed OPC system. Comput. Stand. Interfaces 2009, 31, 984-993. [CrossRef]

39. Salihbegovic, A.; Marinkovic, V.; Cico, Z.; Karavdic, E.; Delic, N. Web based multilayered distributed SCADA/HMI system in refinery application. Comput. Stand. Interfaces 2009, 31, 599-612. [CrossRef]

40. Ferrero, G.; Monclús, H.; Buttiglieri, G.; Comas, J.; Rodríguez-Roda, J. Automatic control system for energy optimization in membrane bioreactors. Desalination 2011, 268, 276-280. [CrossRef]

41. Qi, R.; Qian, H.; Lam, T.L.; Xu, Y.; Zhang, T.; Zhu, W.; Zhang, F.; Liao, J. A new Cartesian cutting robot with laser height control system. In Proceedings of the IEEE International Conference on Mechatronics and Automation, Beijing, China, 7-10 August 2011. [CrossRef]

42. Torrisi, N.M. Monitoring Services for Industrial Applications. IEEE Ind. Electron. Mag. 2011, 5, 49-60. [CrossRef]

43. Aydogmus, O; Talu, M.F. A vision-based measurement installation for programmable logic controllers. Measurement 2012, 45, 1098-1104. [CrossRef]

44. Carlsson, H.; Svensson, B.; Danielsson, F.; Lennartson, B. Methods for reliable simulation-based PLC code verification. IEEE Trans. Ind. Inform. 2012, 8, 267-278. [CrossRef]

45. Sangeetha, A.L.; Naveenkumar, B.; Balaji, A.; Bharathi, N. Experimental validation of PID based cascade control system through SCADA-PLC-OPC and internet architectures. Measurement 2012, 45, 643-649. [CrossRef]

46. Sempere-Payá, V.; Santonja-Climent, S. Integrated sensor and management system for urban waste water networks and prevention of critical situations. Comput. Environ. Urban Syst. 2012, 36, 65-80. [CrossRef]

47. Torrisi, N.M.; de Oliveira, J.F.G. Remote monitoring for high-speed CNC processes over public IP networks using CyberOPC. Int. J. Adv. Manuf. Technol. 2012, 60, 191-200. [CrossRef]

48. Freund, M.; Martin, C.; Braune, A.; Steinkrauss, U. JSUA-An OPC UA JavaScript Framework. In Proceedings of the IEEE 18th Conference on Emerging Technologies \& Factory Automation (ETFA), Cagliari, Italy, 10-13 September 2013. [CrossRef]

49. Eguti, C.C.A.; Gonzaga, L. Design of a robotic orbital driller for assembling aircraft structures. Mechatronics 2014, 24, 533-545. [CrossRef]

50. Da Fonseca, C.C.; Pantoni, R.P.; Brandao, D. Public street lighting remote operation and supervision system. Comput. Stand. Interfaces 2015, 38, 25-34. [CrossRef]

51. Johnsson, O.; Sahlin, D.; Linde, J.; Lidén, G.; Hägglund, T. A mid-ranging control strategy for non-stationary processes and its application to dissolved oxygen control in a bioprocess. Control Eng. Pract. 2015, 42, 89-94. [CrossRef]

52. Alvarado, I.; Limon, D.; Muñoz, D.; Maestre, J.M.; Ridao, M.A.; Scheu, H.; Marquardt, W.; Negenborn, R.R.; De Schutter, B.; Valencia, F; et al. A comparative analysis of distributed MPC techniques applied to the HD-MPC four-tank benchmark. J. Process Control 2011, 21, 800-815. [CrossRef]

53. Mendes, J.; Araújo, R.; Sousa, P.; Apóstolo, F.; Alves, L. An architecture for adaptive fuzzy control in industrial environments. Comput. Ind. 2011, 62, 364-373. [CrossRef]

54. Ferramosca, A.; Limon, D.; Alvarado, I.; Camacho, E.F. Cooperative distributed MPC for tracking. Automatica 2013, 49, 906-914. [CrossRef]

55. Fonseca, J.V.; Ferreira, E.F.M. Increase of PLC computability with neural network for recovery of faults in electrical distribution substation. In Proceedings of the IEEE International Instrumentation and Measurement Technology Conference (I2MTC), Minneapolis, MN, USA, 6-9 May 2013. [CrossRef]

56. Robles, A.; Ruano, M.V.; Ribes, J.; Ferrer, J. Advanced control system for optimal filtration in submerged anaerobic MBRs (SAnMBRs). J. Membr. Sci. 2013, 430, 330-341. [CrossRef] 
57. Craven, S.; Whelan, J.; Glennon, B. Glucose concentration control of a fed-batch mammalian cell bioprocess using a nonlinear model predictive controller. J. Process Control 2014, 24, 344-357. [CrossRef]

58. Czajkowski, A.; Patan, K.; Szymanski, M. Application of the state space neural network to the fault tolerant control system of the PLC-controlled laboratory stand. Eng. Appl. Artif. Intell. 2014, 30, 168-178. [CrossRef]

59. Singh, R.; Sahay, A.; Muzzio, F.; Ierapetritou, M.; Ramachandran, R. A systematic framework for onsite design and implementation of a control system in a continuous tablet manufacturing process. Comput. Chem. Eng. 2014, 66, 186-200. [CrossRef]

60. Ding, J.L.; Wang, F.; Sun, H.; Shang, L. Improved incremental Regularized Extreme Learning Machine Algorithm and its application in two-motor decoupling control. Neurocomputing 2015, 149, 215-223. [CrossRef]

61. Luttmann, R.; Borchert, S.O.; Mueller, C.; Loegering, K.; Aupert, F.; Weyand, S.; Kober, C.; Faber, B.; Cornelissen, G. Sequential/parallel production of potential Malaria vaccines-A direct way from single batch to quasi-continuous integrated production. J. Biotechnol. 2015, 213, 83-96. [CrossRef]

62. Mahmoud, M.S.; Sabih, M.; Elshafei, M. Using OPC technology to support the study of advanced process control. ISA Trans. 2015, 55, 155-167. [CrossRef] [PubMed]

63. Xiaoqiao, W.; Mingzhou, L.; Maogen, G.; Lin, L.; Conghu, L. Research on assembly quality adaptive control system for complex mechanical products assembly process under uncertainty. Comput. Ind. 2015, 74, 43-57. [CrossRef]

64. González, I.; Calderón, A.J.; Mejías, A.; Andújar, J.M. Novel networked remote laboratory architecture for open connectivity based on PLC-OPC-LabVIEW-EJS integration. Application to remote fuzzy control and sensors data acquisition. Sensors 2016, 16, 1822. [CrossRef]

65. Hinojosa, A.I.; Ferramosca, A.; González, A.H.; Odloak, D. One-layer gradient-based MPC + RTO of a propylene/propane splitter. Comput. Chem. Eng. 2017, 106, 160-170. [CrossRef]

66. Zhang, S.; Tang, Q.; Lin, Y.; Tang, Y. Fault detection of feed water treatment process using PCA-WD with parameter optimization. ISA Trans. 2017, 68, 313-326. [CrossRef] [PubMed]

67. Li, Z.; Li, P.; Wu, M. Digital oil and gas pipeline visualization using X3D. In Proceedings of the 14th International Conference on 3D Web Technology, Darmstadt, Germany, 16-17 June 2009. [CrossRef]

68. Sánchez, A.; Escaño, J.M.; Bordons, C. Simulator for control and automation using an interactive and configurable 3D virtual environment. In Proceedings of the 2012 SICE Annual Conference (SICE), Akita, Japan, 20-23 August 2012.

69. Skripcak, T.; Tanuska, P.; Konrad, U.; Schmeisser, N. Toward nonconventional human-machine interfaces for supervisory plant process monitoring. IEEE Trans. Hum. Mach. Syst. 2013, 43, 437-450. [CrossRef]

70. Hincapié, M.; Ramírez, M.J.; Valenzuela, A.; Valdez, J.A. Mixing real and virtual components in automated manufacturing systems using PLM tools. Int. J. Interact. Des. Manuf. 2014, 8, 209-230. [CrossRef]

71. Zamarreño, J.M.; Mazaeda, R.; Caminero, J.A.; Rivero, A.J.; Arroyo, J.C. A new plug-in for the creation of OPC servers based on EcosimPro@ simulation software. Simul. Model. Pract. Theory 2014, 40, 86-94. [CrossRef]

72. Galambos, P.; Csapó, A.; Zentay, P.; Fülöp, I.M.; Haidegger, T.; Baranyi, P.; Rudas, I.J. Design, programming and orchestration of heterogeneous manufacturing systems through VR-powered remote collaboration. Robot. Comput. Integr. Manuf. 2015, 33, 68-77. [CrossRef]

73. Rodríguez, F.; Castilla, M.; Sánchez, J.A.; Pawlowski, A. Semi-virtual Plant for the Modelling, Control and Supervision of batch-processes. An example of a greenhouse irrigation system. IFAC-PapersOnLine 2015, 48, 123-128. [CrossRef]

74. Dai, W.; Zhou, P.; Zhao, D.; Lu, S.; Chai, T. Hardware-in-the-loop simulation platform for supervisory control of mineral grinding process. Powder Tecnol. 2016, 288, 422-434. [CrossRef]

75. Surisetty, K.; Siegler, H.H.; McCaffrey, W.; Ben-Zvi, A. Robust modeling of a microalgal heterotrophic fed-batch bioreactor. Chem. Eng. Sci. 2010, 65, 5402-5410. [CrossRef]

76. Iacob, M.; Andreescu, G.D. Real-Time Hardware-in-the-Loop Test Platform for Thermal Power Plant Control Systems. In Proceedings of the IEEE 9th International Symposium on Intelligent Systems and Informatics, Subotica, Serbia, 8-10 September 2011.

77. Ziogou, C.; Ipsakis, D.; Elmasides, C.; Stergiopoulos, F.; Papadopoulou, S.; Seferlis, P.; Voutetakis, S. Automation infrastructure and operation control strategy in a stand-alone power system based on renewable energy sources. J. Power Sources 2011, 196, 9488-9499. [CrossRef] 
78. Ziogou, C.; Ipsakis, D.; Stergiopoulos, F.; Papadopoulou, S.; Bezergianni, S.; Voutetakis, S. Infrastructure, automation and model-based operation strategy in a stand-alone hydrolytic solar-hydrogen production unit. Int. J. Hydrog. Energy 2012, 37, 16591-16603. [CrossRef]

79. Nguyen, T.H.; Prinz, A.; Friiso, T.; Nossum, R.; Tyapin, I. A framework for data integration of offshore wind farms. Renew. Energy 2013, 60, 150-161. [CrossRef]

80. Calderón, A.J.; González, I.; Calderón, M. Management of a PEM electrolyzer in hybrid renewable energy systems. In Fuzzy Modeling and Control: Theory and Applications; Atlantis Press: Amsterdam, The Netherlands, 2014; pp. 217-234.

81. De Andrade, G.A.; Álvarez, J.D.; Pagano, D.J.; Berenguel, M. Nonlinear controllers for solar thermal plants: A comparative study. Control Eng. Pract. 2015, 43, 12-20. [CrossRef]

82. González, I.; Calderón, A.J.; Calderón Godoy, M.; Herrero, J.L. Monitoring of Electric Power Systems: Application to self-sufficient Hybrid Renewable Energy Systems. In Proceedings of the IEEE 9th International Conference on Compatibility and Power Electronics (CPE), Caparica, Portugal, 24-26 June 2015. [CrossRef]

83. González, I.; Calderón, A.J.; Calderón Godoy, M.; Ramiro, A. Experimental automation platform of stand-alone hybrid renewable energy systems: Fuzzy logic application and exergy analysis. In Proceedings of the 6th International Renewable Energy Congress (IREC), Sousse, Tunisia, 24-26 March 2015. [CrossRef]

84. Koller, M.; Borsche, T.; Ulbig, A.; Andersson, G. Review of grid applications with the Zurich 1 MW battery energy storage system. Electr. Power Syst. Res. 2015, 120, 128-135. [CrossRef]

85. Alizadeh, S.M.; Ozansoy, C. The role of communications and standardization in wind power applications-A review. Renew. Sustain. Energy Rev. 2016, 54, 944-958. [CrossRef]

86. Baumann, L.; Boggasch, E. Experimental assessment of hydrogen systems and vanadium-redox-flow-batteries for increasing the self-consumption of photovoltaic energy in buildings. Int. J. Hydrogen Energy 2016, 41, 740-751. [CrossRef]

87. Silvestre, S.; Mora-López, L.; Kichou, S.; Sánchez-Pacheco, F.; Domínguez-Pumar, M. Remote supervision and fault detection on OPC monitored PV systems. Sol. Energy 2016, 137, 424-433. [CrossRef]

88. Sayed, K.; Gabbar, H.A. SCADA and smart energy grid control automation. In Smart Energy Grid Engineering; Gabbar, H.A., Ed.; Academic Press: New York, NY, USA, 2017; ISBN 978-0-12-805343-0.

89. Järventausta, P.; Repo, S.; Rautiainen, A.; Partanen, J. Smart grid power system control in distributed generation environment. Annu. Rev. Control 2010, 34, 277-286. [CrossRef]

90. Tsiamitros, D.; Stimoniaris, D.; Poulakis, N.; Zehir, M.A.; Batman, A.; Bagriyanik, M.; Ozdemir, A.; Dialynas, E. Advanced energy storage and demand-side management in smart grids using buildings energy efficiency technologies. In Proceedings of the 5th IEEE PES Innovative Smart Grid Technologies Europe (ISGT Europe), Istanbul, Turkey, 12-15 October 2014. [CrossRef]

91. Cintuglu, M.H.; Mohammed, O.A. Multiagent-based decentralized operation of microgrids considering data interoperability. In Proceedings of the IEEE International Conference on Smart Grid Communications (SmartGridComm), Miami, FL, USA, 2-5 November 2015. [CrossRef]

92. Pereira, R.; Figueiredo, J.; Melicio, R.; Mendes, V.M.F.; Martins, J.; Quadrado, J.C. Consumer energy management system with integration of smart meters. Energy Rep. 2015, 1, 22-29. [CrossRef]

93. Pinceti, P.; Vanti, M.; Brocca, C.; Carnessechi, M.; Macera, G.P. Design criteria for a power management system for microgrids with renewable sources. Electr. Power Syst. Res. 2015, 122, 168-179. [CrossRef]

94. Arnone, D.; Bertoncini, M.; Paternò, G.; Rossi, A.; Ippolito, M.G.; Sanseverino, E.R. Multi-objective Optimization of Energy Hubs at the Crossroad of Three Energy Distribution Networks. In Proceedings of the 6th International Conference on Smart Grids, Green Communications and IT Energy-aware Technologies, Lisbon, Portugal, 26-30 June 2016.

95. Büscher, M.; Kube, M.; Piech, K.; Lehnhoff, S.; Rohjans, S.; Fischer, L. Towards Smart Grid-ready substations: A standard-compliant protection system. In Proceedings of the 19th Power Systems Computation Conference (PSCC), Genoa, Italy, 24-26 June 2016. [CrossRef]

96. Cintuglu, M.H.; Mohammed, O.A.; Akkaya, K.; Uluagac, A.S. A Survey on Smart Grid Cyber-Physical System Testbeds. IEEE Commun. Surv. Tutor. 2016, 19, 446-464. [CrossRef]

97. Manbachi, M.; Sadu, A.; Farhangi, H.; Monti, A.; Palizban, A.; Ponci, F.; Arzanpour, S. Impact of EV penetration on Volt-VAR Optimization of distribution networks using real-time co-simulation monitoring platform. Appl. Energy 2016, 169, 28-39. [CrossRef] 
98. Mendes, P.R.C.; Valverde, L.; Bordons, C.; Normey-Rico, J.E. Energy management of an experimental microgrid coupled to a V2G system. J. Power Sources 2016, 327, 702-713. [CrossRef]

99. Nguyen, V.H.; Tran, Q.T.; Besanger, Y. SCADA as a service approach for interoperability of micro-grid platforms. Sustain. Energy Grids Netw. 2016, 8, 26-36. [CrossRef]

100. Petrollese, M.; Valverde, L.; Cocco, D.; Cau, G.; Guerra, J. Real-time integration of optimal generation scheduling with MPC for the energy management of a renewable hydrogen-based microgrid. Appl. Energy 2016, 166, 96-106. [CrossRef]

101. Valverde, L.; Rosa, F.; Bordons, C.; Guerra, J. Energy Management Strategies in hydrogen Smart-Grids: A laboratory experience. Int. J. Hydrogen Energy 2016, 41, 13715-13725. [CrossRef]

102. Bouallaga, A.; Davigny, A.; Courtecuisse, V.; Robyns, B. Methodology for technical and economic assessment of electric vehicles integration in distribution grid. Math. Comput. Simul. 2017, 131, 172-189. [CrossRef]

103. González, I.; Calderón, A.J.; Andújar, J.M. Novel Remote Monitoring Platform for RES-Hydrogen based Smart Microgrid. Energy Convers. Manag. 2017, 148, 489-505. [CrossRef]

104. Kapsalis, V.; Koubias, S.; Papadopoulos, G. OPC-SMS: A wireless gateway to OPC-based data sources. Comput. Stand. Interfaces 2002, 24, 437-451. [CrossRef]

105. Henriques, E.; Figueiredo, J. Energy Management in Intelligent Buildings using Predictive Control. IFAC Proc. Vol. 2010, 43, 104-109. [CrossRef]

106. Figueiredo, J.; Sá da Costa, J. A SCADA system for energy management in intelligent buildings. Energy Build. 2012, 49, 85-98. [CrossRef]

107. Bhatt, J.; Verma, H.K. Design and development of wired building automation systems. Energy Build. 2015, 103, 396-413. [CrossRef]

108. Domingues, P.; Carreira, P.; Vieira, R.; Kastner, W. Building automation systems: Concepts and technology review. Comput. Stand. Interfaces 2016, 45, 1-12. [CrossRef]

109. Ungurean, I.; Gaitan, N.C. Monitoring and control system for smart buildings based on OPC UA specifications. In Proceedings of the International Conference on Development and Application Systems (DAS), Suceava, Romania, 19-21 May 2016. [CrossRef]

110. Li, X.; Zhao, T.; Zhang, J.; Chen, T. Development of network control platform for energy saving of fan coil units. J. Build. Eng. 2017, 12, 155-160. [CrossRef]

111. Du Plessis, G.E.; Liebenberg, L.; Mathews, E.H.; Du Plessis, J.N. A versatile energy management system for large integrated cooling systems. Energy Convers. Manag. 2013, 66, 312-325. [CrossRef]

112. Végh, J.; Pós, I.; Horváth, C.; Kálya, Z.; Parkó, T.; Ignits, M. VERONA V6.22-An enhanced reactor analysis tool applied for continuous core parameter monitoring at Paks NPP. Nucl. Eng. Des. 2015, 292, 261-276. [CrossRef]

113. Wang, W.; Yang, M. Implementation of an integrated real-time process surveillance and diagnostic system for nuclear power plants. Ann. Nucl. Energy 2016, 97, 7-26. [CrossRef]

114. Tejeda, A.; Riviere, P.; Marchio, D.; Cauret, O.; Milu, A. Hardware in the loop test bench using Modelica: A platform to test and improve the control of heating systems. Appl. Energy 2017, 188, 107-120. [CrossRef]

115. Klein, A.; Wozny, G. Web Based Remote Experiments for Chemical Engineering Education: The Online Distillation Column. Educ. Chem. Eng. 2006, 1, 134-138. [CrossRef]

116. Schaf, F.M.; Muller, D.; Bruns, F.W.; Pereira, C.E.; Erbe, H.-H. Collaborative learning and engineering workspaces. Annu. Rev. Control 2009, 33, 246-252. [CrossRef]

117. Golob, M.; Bratina, B. Web-based monitoring and control of industrial processes used for control education. IFAC Proc. Vol. 2013, 46, 162-167. [CrossRef]

118. Domínguez, M.; Alonso, S.; Fuertes, J.J.; Prada, M.A.; Morán, A.; Barrientos, P. OPC-DB link for the management of new systems in a remote laboratory. IFAC Proc. Vol. 2014, 47, 9715-9720. [CrossRef]

119. Aydogmus, O. A web-based educational tool using programmable logic controller-connected MATLAB-OPC server. Int. J. Electr. Eng. Educ. 2015, 52, 71-80. [CrossRef]

120. Kafuko, M.; Wanyama, T. Integrated Hands-on and Remote PID Tuning Laboratory. In Proceedings of the 2015 Canadian Engineering Education Association (CEEA15) Conference, Hamilton, ON, Canada, 31 May-3 June 2015.

121. Prada, M.A.; Fuertes, J.J.; Alonso, S.; García, S.; Domínguez, M. Challenges and solutions in remote laboratories. Application to a remote laboratory of an electro-pneumatic classification cell. Comput. Educ. 2015, 85, 180-190. [CrossRef] 
122. Calderón, A.J.; González, I. Plataforma Hardware-in-the-Loop basada en LabVIEW, PLC y OPC. Experiencia de uso docente en automatización y supervisión. In Proceedings of the 24 Congreso Universitario de Innovación Educativa en las Enseñanzas Técnicas (CUIEET), Cádiz, Espana, 21-23 September 2016.

123. Simons, S.; Abe, P.; Nese, S. Learning in the AutFab-The fully automated Industrie 4.0 learning factory of the University of Applied Sciences Darmstadt. Procedia Manuf. 2017, 9, 81-88. [CrossRef]

124. Lee, J.; Lapira, E.; Bagheri, B.; Kao, H. Recent advances and trends in predictive manufacturing systems in big data environment. Manuf. Lett. 2013, 1, 38-41. [CrossRef]

125. López-Campos, M.A.; Crespo-Márquez, A.; Gómez-Fernández, J.F. Modelling using UML and BPMN the integration of open reliability, maintenance and condition monitoring management systems: An application in an electric transformer system. Comput. Ind. 2013, 64, 524-542. [CrossRef]

126. Lee, J.; Wu, F.; Zhao, W.; Ghaffari, M.; Liao, L.; Siegel, D. Prognostics and health management design for rotary machinery systems-Reviews, methodology and applications. Mech. Syst. Signal Process. 2014, 42, 314-334. [CrossRef]

127. Selak, L.; Butala, P.; Sluga, A. Condition monitoring and fault diagnostics for hydropower plants. Comput. Ind. 2014, 65, 924-936. [CrossRef]

128. Mourtzis, D.; Vlachou, E.; Milas, N. Industrial Big Data as a Result of IoT Adoption in Manufacturing. Procedia CIRP 2016, 55, 290-295. [CrossRef]

129. Zuehlke, D. SmartFactory-Towards a factory-of-things. Annu. Rev. Control 2010, 34, 129-138. [CrossRef]

130. Neugschwandtner, G.; Reekmans, M.; van der Linden, D. An open automation architecture for flexible manufacturing. In Proceedings of the IEEE 18th Conference on Emerging Technologies \& Factory Automation (ETFA), Cagliari, Italy, 10-13 September 2013. [CrossRef]

131. Kannengiesser, U.; Neubauer, M.; Heininger, R. Subject-oriented BPM as the glue for integrating enterprise processes in smart factories. In On the Move to Meaningful Internet Systems: OTM 2015 Workshops; Lecture Notes in Computer Science; Springer: Luxembourg, 2015; Volume 9416, pp. 77-86.

132. Palm, F.; Grüner, S.; Pfrommer, J.; Graube, M.; Urbas, L. Open source as enabler for OPC UA in industrial automation. In Proceedings of the 20th IEEE Conference on Emerging Technologies \& Factory Automation (ETFA), Luxembourg, 8-11 September 2015. [CrossRef]

133. Schlechtendahl, J.; Keinert, M.; Kretschmer, F.; Lechler, A.; Verl, A. Making existing production systems Industry 4.0-ready. Prod. Eng. 2015, 9, 143-148. [CrossRef]

134. Toro, C.; Barandiaran, I.; Posada, J. A perspective on knowledge based intelligent systems implementation in Industrie 4.0. Procedia Comput. Sci. 2015, 60, 362-370. [CrossRef]

135. Berger, C.; Hees, A.; Braunreuther, S.; Reinhart, G. Characterization of Cyber-Physical Sensor Systems. Procedia CIRP 2016, 41, 638-643. [CrossRef]

136. Fleischmann, H.; Kohl, J.; Franke, J. A reference architecture for the development of socio-cyber-physical condition monitoring systems. In Proceedings of the 11th System of Systems Engineering Conference, Kongsberg, Norway, 12-16 June 2016. [CrossRef]

137. García, M.V.; Irisarri, E.; Pérez, F.; Estévez, E.; Marcos, M. OPC-UA Communications Integration using a CPPS architecture. In Proceedings of the IEEE Ecuador Technical Chapters Meeting (ETCM), Guayaquil, Ecuador, 12-14 October 2016. [CrossRef]

138. Harrison, R.; Vera, D.; Ahmad, B. EngineeringMethods and Tools for Cyber-Physical Automation Systems. Proc. IEEE 2016, 104, 973-985. [CrossRef]

139. Hoffmann, M.; Büscher, C.; Meisen, T.; Jeschke, S. Continuous integration of field level production data into top-level information systems using the OPC interface standard. Procedia CIRP 2016, 41, 496-501. [CrossRef]

140. Iatrou, C.P.; Urbas, L. OPC UA Hardware Offloading Engine as dedicated peripheral IP Core. In Proceedings of the 12th IEEE World Conference on Factory Communication Systems (WFCS), Aveiro, Portugal, 3-6 May 2016. [CrossRef]

141. Schleipen, M.; Gilani, S.S.; Bischoff, T.; Pfrommer, J. OPC UA \& Industrie 4.0—Enabling technology with high diversity and variability. Procedia CIRP 2016, 57, 315-320. [CrossRef]

142. Brecher, C.; Ecker, C.; Herfs, W.; Obdenbusch, M.; Jeschke, S.; Hoffmann, M.; Meisen, T. The need of dynamic and adaptive data models for cyber-physical production systems. In Cyber-Physical Systems: Foundations, Principles and Applications; Elsevier: Amsterdam, The Netherlands, 2017; ISBN1 978-012803874-1. ISBN2 978-012803801-7. 
143. Krüger, J.; Wang, L.; Verl, A.; Bauernhansl, T.; Carpanzano, E.; Makris, S.; Fleischer, J.; Reinhart, G.; Franke, J.; Pellegrinelli, S. Innovative control of assembly systems and lines. CIRP Ann. Manuf. Technol. 2017, 66, 707-730. [CrossRef]

144. Liu, C.; Xu, X. Cyber-physical Machine Tool-The Era of Machine Tool 4.0. Procedia CIRP 2017, 63, 70-75. [CrossRef]

145. Profanter, S.; Dorofeev, K.; Zoitl, A. OPC UA for Plug \& Produce: Automatic Device Discovery using LDS-ME. In Proceedings of the 22nd IEEE International Conference on Emerging Technologies and Factory Automation (ETFA), Cyprus, Greece, 12-15 September 2017.

146. Wollschlaeger, M.; Sauter, T.; Jasperneite, J. The Future of Industrial Communication. Automation Networks in the Era of the Internet of Things and Industry 4.0. IEEE Ind. Electron. Mag. 2017, 11, 17-27. [CrossRef]

147. Cândido, G.; Jammes, F.; Barata, J.; Colombo, A.W. SOA at Device level in the Industrial domain: Assessment of OPC UA and DPWS specifications. In Proceedings of the 8th IEEE International Conference on Industrial Informatics (INDIN), Osaka, Japan, 13-16 July 2010. [CrossRef]

148. Miyazawa, K.; Murakami, M.; Matsukuma, T.; Fukushima, K.; Maruyama, Y.; Matsumoto, M.; Kawamoto, J.; Yamashita, E. OPC UA Information Model, Data Exchange, Safety and Security for IEC 61131-3. In Proceedings of the Society of Instrument and Control Engineers (SICE) Annual Conference, Tokyo, Japan, 13-18 September 2011.

149. Granzer, W.; Kastner, W. Information modeling in heterogeneous Building Automation Systems. In Proceedings of the 9th International Workshop on Factory Communication Systems (WFCS), Lemgo/Detmold, Germany, 21-24 May 2012. [CrossRef]

150. Rohjans, S.; Piech, K.; Lehnhoff, S. UML-based modelling of OPC UA address spaces for power systems. In Proceedings of the 2013 IEEE International Workshop on Intelligent Energy Systems (IWIES), Vienna, Austria, 14 November 2013. [CrossRef]

151. Girbea, A.; Suciu, C.; Nechifor, S.; Sisak, F. Design and implementation of a service-oriented architecture for the optimization of industrial applications. IEEE Trans. Ind. Inform. 2014, 10, 185-196. [CrossRef]

152. Sucic, S.; Havelka, J.G.; Dragicevic, T. A device-level service-oriented middleware platform for self-manageable DC microgrid applications utilizing semantic-enabled distributed energy resources. Electr. Power Energy Syst. 2014, 54, 576-588. [CrossRef]

153. Frühwirth, T.; Pauker, F.; Fernbach, A.; Ayatollahi, I.; Kastner, W.; Kittl, B. Guarded state machines in OPC UA. In Proceedings of the 41st Annual Conference of the IEEE Industrial Electronics Society, IECON2015, Yokohama, Japan, 9-12 November 2015.

154. Schleipen, M.; Selyansky, E.; Henssen, R.; Bischoff, T. Multi-level user and role concept for a secure plug-and-work based on OPC UA and AutomationML. In Proceedings of the 20th IEEE Conference on Emerging Technologies \& Factory Automation (ETFA), Luxembourg, 8-11 September 2015. [CrossRef]

155. Azaiez, S.; Boc, M.; Cudennec, L.; Da Silva Simoes, M.; Haupert, J.; Kchir, S.; Klinge, X.; Labidi, W.; Nahhal, K.; Pfrommer, J.; et al. Towards Flexibility in Future Industrial Manufacturing: A Global Framework for Self-Organization of Production Cells. Procedia Comput. Sci. 2016, 83, 1268-1273. [CrossRef]

156. Cavalieri, S.; Regalbuto, A. Integration of IEC 61850 SCL and OPC UA to improve interoperability in Smart Grid environment. Comput. Stand. Interfaces 2016, 47,77-99. [CrossRef]

157. Grüner, S.; Pfrommer, J.; Palm, F. RESTful industrial communication with OPC UA. IEEE Trans. Ind. Inform. 2016, 12, 1832-1841. [CrossRef]

158. Kozar, S.; Kadera, P. Integration of IEC 61499 with OPC UA. In Proceedings of the IEEE 21st International Conference on Emerging Technologies and Factory Automation (ETFA), Berlin, Germany, 6-9 September 2016. [CrossRef]

159. Nguyen, V.H.; Bessanger, Y.; Tran, Q.T. CIM and OPC UA for interoperability of micro-grid platforms. In Proceedings of the IEEE Power \& Energy Society Innovative Smart Grid Technologies Conference (ISGT), Minneapolis, MN, USA, 6-9 September 2016. [CrossRef]

160. Pauker, F.; Frühwirth, T.; Kittl, B.; Kastner, W. A Systematic Approach to OPC UA Information Model Design. Procedia CIRP 2016, 57, 321-326. [CrossRef]

161. Pfrommer, J.; Grüner, S.; Palm, F. Hybrid OPC UA and DDS: Combining architectural styles for the industrial internet. In Proceedings of the IEEE Word Conference on Factory Automation Systems (WFCS), Aveiro, Portugal, 3-6 May 2016. [CrossRef] 
162. Seilonen, I.; Tuovinen, T.; Elovaara, J.; Tuomi, I.; Oksanen, T. Aggregating OPC UA servers for monitoring manufacturing systems and mobile work machines. In Proceedings of the IEEE 21st International Conference on Emerging Technologies and Factory Automation (ETFA), Berlin, Germany, 6-9 September 2016. [CrossRef]

163. Shin, I.J.; Song, B.K.; Eom, D.S. Auto-Mapping and Configuration Method of IEC 61850 Information Model Based on OPC UA. Energies 2016, 9, 901. [CrossRef]

164. Sucic, S.; Capuder, T. Automation of flexible distributed multi-generation systems by utilizing optimized middleware platform. Appl. Energy 2016, 169, 542-554. [CrossRef]

165. Dorofeev, K.; Cheng, C.H.; Ferreira, P.; Guedes, M.; Profanter, S.; Zoitl, A. Device Adapter Concept towards Enabling Plug\&Produce Production Environments. In Proceedings of the 22nd IEEE International Conference on Emerging Technologies and Factory Automation (ETFA), Cyprus, Greece, 12-15 September 2017.

166. Lee, B.; Kim, D.K.; Yang, H.; Oh, Y. Model transformation between OPCU UA and UML. Comput. Stand. Interfaces 2017, 50, 236-250. [CrossRef]

167. Nicholson, A.; Webber, S.; Dyer, S.; Patel, T.; Janicke, H. SCADA security in the light of Cyber-Warfare. Comput. Secur. 2012, 31, 418-436. [CrossRef]

168. Wu, K.; Li, Y.; Chen, L.; Wang, Z. Research of Integrity and Authentication in OPC UA Communication Using Whirlpool Hash Function. Appl. Sci. 2015, 5, 446-458. [CrossRef]

169. Leszczyna, R. Cybersecurity and Privacy in Standards for Smart Grids-A Comprehensive Survey. Comput. Stand. Interfaces 2018, 56, 62-73. [CrossRef]

170. Staggs, J.; Ferlemann, D.; Shenoi, S. Wind farm security: Attack surface, targets, scenarios and mitigation. Int. J. Crit. Infrastruct. Prot. 2017, 17, 3-14. [CrossRef]

171. Escorza, V.A.; Guedea, F. A wireless sensors network development for environmental monitoring using OPC Unified Architecture in a generic manufacturing system. In Proceedings of the 2014 International Conference on Mechatronics, Electronics and Automotive Engineering (ICMEAE), Cuernavaca, Mexico, 18-21 November 2014. [CrossRef]

172. Akerman, M.; Fast-Berglund, A.; Ekered, S. Interoperability for a dynamic assembly system. Procedia CIRP 2016, 44, 407-411. [CrossRef]

173. Oksanen, T.; Piirainen, P.; Seilonen, I. Remote access of ISO 11783 process data by using OPC Unified Architecture technology. Comput. Electron. Agric. 2015, 117, 141-148. [CrossRef]

174. Oksanen, T.; Linkolehto, R.; Seilonen, I. Adapting an industrial automation protocol to remote monitoring of mobile agricultural machinery: A combine harvester with IoT. IFAC-PapersOnLine 2016, 49, 127-131. [CrossRef]

175. Erd, M.; Schaeffer, F.; Kostic, M.; Reindl, L.M. Event monitoring in emergency scenarios using energy efficient wireless sensor nodes for the disaster information management. Int. J. Disaster Risk Reduct. 2016, 16, $33-42$. [CrossRef]

176. Farnham, B.; Barillère, R. Migration from OPC-DA to OPC-UA. In Proceedings of the 13th International Conference on Accelerator \& Large Experimental Physics Control Systems (ICALEPCS2011), Grenoble, France, 10-14 October 2011.

177. Abbon, P.; Adolph, C.; Akhunzyanov, R.; Alexandrov, Y.; Alexeev, M.G.; Alexeev, G.D.; Amoroso, A.; Andrieux, V.; Anosov, V.; Austregesilo, A.; et al. The COMPASS setup for physics with hadron beams. Nucl. Instrum. Methods Phys. Res. A 2015, 779, 69-115. [CrossRef]

178. Masand, H.; Kumar, A.; Bhandarkar, M.; Mahajan, K.; Gulati, H.; Dhongde, J.; Patel, K.; Chudasma, H.; Pradhan, S. Machine Control System of Steady State Superconducting Tokamak-1. Fusion Eng. Des. 2016, 112, 731-734. [CrossRef]

179. Project Information Modelling in Automation webpage. Available online: http://www.innovatienetwerk.be/ attachments/get/4137/Eindverslag_IMA_TETRA_110131.pdf (accessed on 20 January 2019).

180. Project SO-PC-Pro webpage. Available online: http://www.skillpro-project.eu/ (accessed on 20 January 2019).

181. Project CLAFIS webpage. Available online: http://clafis-project.eu/index.php/project (accessed on 20 January 2019).

182. Project SO-PC-Pro webpage. Available online: http://sopcpropub.ce.jku.at/ (accessed on 20 January 2019).

183. Project OPC4Factory webpage. Available online: https://www.auto.tuwien.ac.at/index.php/projectsites/146opc4factory (accessed on 20 January 2019).

184. Project INGRID webpage. Available online: http://www.ingridproject.eu/ (accessed on 20 January 2019).

185. Project open62541 webpage. Available online: http://open62541.org/ (accessed on 20 January 2019).

186. Project FreeOpcUA webpage. Available online: https://github.com/FreeOpcUa (accessed on 20 January 2019). 
187. Project OpenOpcUA webpage. Available online: http://www.openopcua.org/ (accessed on 22 January 2019).

188. Project MORE-NMP webpage. Available online: http://www.more-nmp.eu/ (accessed on 22 January 2019).

189. Project openMOS webpage. Available online: https://www.openmos.eu/ (accessed on 22 January 2019).

190. Project PERFoRM webpage. Available online: http://www.horizon2020-perform.eu/ (accessed on 22 January 2019).

191. OPC Foundation Markets \& Collaborations, PLCopen. Available online: https://opcfoundation.org/marketscollaboration/plcopen/ (accessed on 22 January 2019).

192. OPC Foundation News, Press Release about MTConnect companion specification. Available online: https:/opcfoundation.org/news/press-releases/mtconnect-institute-opc-foundation-announce-availabilitycompanion-specification-release-candidate/ (accessed on 25 January 2019).

193. OPC Foundation News, W3C and OPCF collaboration webpage. Available online: https://opcfoundation. org/news/opc-foundation-news/w3c-and-opcf-to-integrate-opc-ua-into-the-web-of-things/ (accessed on 25 January 2019).

194. OPC Foundation News, Press Release about PubSub extension. Available online: https://opcfoundation.org/news/pressreleases/opc-foundation-announces-opc-ua-pubsub-release-important-extension-opc-ua-communication-platform/ (accessed on 25 January 2019).

195. Bosch Industry 4.0 webpage. Available online: https://www.bosch.com/products-and-services/connectedproducts-and-services/industry-4-0/ (accessed on 25 January 2019).

196. Schneider Electric Innovation webpage. Available online: https://www.schneider-electric.com/en/work/ campaign/innovation/overview.jsp (accessed on 27 January 2019).

197. Siemens Digital Enterprise webpage. Available online: https://www.siemens.com/global/en/home/company/ topic-areas/future-of-manufacturing/digital-enterprise.html (accessed on 27 January 2019).

198. Rockwell Automation Connected Enterprise webpage. Available online: https://www.rockwellautomation. com/global/capabilities/connected-enterprise/overview.page (accessed on 27 January 2019).

199. Microsoft Connected Factory webpage. Available online: https:/www.microsoft.com/en-us/internet-ofthings/connected-factory (accessed on 27 January 2019).

200. OPC Foundation Security Bulletins. Available online: https://opcfoundation.org/security/ (accessed on 26 January 2019).

201. Calderón, A.J.; González, I. Integration of Sensor and Actuator Networks and the SCADA System to Promote the Migration of the Legacy Flexible Manufacturing System towards the Industry 4.0 Concept. J. Sens. Actuator Netw. 2018, 7, 23. [CrossRef]

202. Gorecky, D.; Scmitt, M.; Loskyll, M.; Zühlke, D. Human-Machine-Interaction in the Industry 4.0 Era. In Proceedings of the 12th IEEE International Conference on Industrial Informatics (INDIN), Porto Alegre, Brazil, 37-30 July 2014. [CrossRef]

203. NetIC IOT product information. Available online: https://www.hilscher.com/netic-iot/ (accessed on 23 January 2019).

204. OPC Foundation Article about Industrie 4.0. Available online: https://opcconnect.opcfoundation.org/2017/ 06/there-is-no-industrie-4-0-without-opc-ua/ (accessed on 23 January 2019).

(C) 2019 by the authors. Licensee MDPI, Basel, Switzerland. This article is an open access article distributed under the terms and conditions of the Creative Commons Attribution (CC BY) license (http://creativecommons.org/licenses/by/4.0/). 